\title{
Bankruptcy in General Equilibrium
}

\author{
by \\ Tarun Sabarwal ${ }^{1}$ \\ Mail Stop 93 \\ Federal Reserve Board \\ Washington, DC 20551. \\ tarun.sabarwal@frb.gov
}

First Draft: August 1998

This Version: October 23, 2000

\begin{abstract}
In this paper, I construct a model of an exchange economy in which bankruptcy arises in a manner similar to what we observe. This model is a more realistic representation of some markets in which intertemporal assets are traded. Using standard and natural assumptions, I show that every economy represented by this model has an equilibrium. Using examples, I highlight some welfare effects of bankruptcy.
\end{abstract}

JEL Numbers: C620, D410, D500, D520, D610, D800

Keywords: Bankruptcy, General Equilibrium, Incomplete Markets, Exemption, Credit Limit

\footnotetext{
${ }^{1}$ I am deeply grateful to Bob Anderson and Chris Shannon for their advice and encouragement. I also thank Roko Aliprantis, Aloisio Araujo, Peter Bardsley, Alberto Bisin, Federico Echenique, John Geanakoplos, Piero Gottardi, John Hillas, Kathleen Johnson, Andreas Lehnert, Heracles Polemarchakis, Martin Shubik, Rabee Tourky, Nicholas Yannelis, Bill Zame and seminar audiences at SITE (July 1999) and at the GE Conference at NYU (April 2000) for their suggestions and encouragement.

This paper is a revised version of two chapters of my doctoral dissertation in economics, filed at U.C. Berkeley in April 2000.

The views in this paper are those of the author and not necessarily those of the Federal Reserve Board or its staff.
} 


\section{Introduction}

In recent years, total indebtedness has increased greatly and a greater proportion of this debt is being traded in asset markets through securitized pools of assets. For example, using data from the Flow of Funds accounts of the United States, we see that from the end of 1990 to the end of the first quarter of 2000 , total consumer credit outstanding has increased from $\$ 0.8$ trillion to $\$ 1.4$ trillion and total mortgages outstanding from $\$ 3.8$ trillion to $\$ 6.5$ trillion. Over the same period, the proportion of consumer credit traded in asset markets through securitized pools of assets has grown from $9.5 \%$ to $30.6 \%$ and the proportion of total mortgages from $28.6 \%$ to $46.0 \%{ }^{2}$

Also, the number of personal bankruptcies has increased greatly. For example, in the United States, total personal (non-business) bankruptcies increased from about 286 thousand for the twelve months ended March 31, 1985 to about 787 thousand for the twelve months ended March 31, 1995 to about 1.3 million for the twelve months ended March 31, 2000. ${ }^{3}$

These observations imply that there is a greater chance that a debtor's debt is being traded in asset markets through a securitized pool of assets and that a bankruptcy affects creditors invested in such pools. Because agents can be buyers of some assets and sellers of others, default by some debtors leads to partial recovery for their creditors and this might force these creditors to default on their debt to others. This can set off a chain reaction resulting in widespread default and bankruptcy. As more and more people invest in asset markets (either directly or indirectly) these chain reactions can potentially affect a large proportion of the population.

Thus, it becomes important to understand how bankruptcies filter through and affect investors in a securitized pool of assets, how they affect recovery rates on assets and how they affect trading and the allocation of resources through the mechanism of markets. To do this, it is important to understand the legal framework governing bankruptcy (for example, the rights of creditors and debtors in bankruptcy law and the role of exemptions) and the trading institutions governing credit (for example, the effects of credit limits on asset trade and the role of an agent's default history in determining his credit limit and future trading ability). In this paper, I construct a model

\footnotetext{
${ }^{2}$ An even higher proportion of revolving consumer credit is securitized. According to Statistical Release G.19 of the Board of Governors of the Federal Reserve System (August 2000), at the end of the first quarter of 2000, pools of securitized assets were $52.6 \%$ of revolving consumer credit; which stood at $\$ 609$ billion.

${ }^{3}$ Source: Administrative Office of the U.S. Courts (News Release; June 9, 2000) and earlier data. Also, personal bankruptcies account for most of the bankruptcies. In 1985 they were $81.5 \%$ of all bankruptcies, in 1995 they were $93.8 \%$ and in 2000 they were $97.1 \%$.
} 
of an exchange economy that can be used to analyze these issues. The view in this paper (and also in some of the other papers mentioned below) is that default and bankruptcy are important economic phenomena that can be part of an economic equilibrium with competitive markets and these phenomena are consistent with smoothly functioning asset markets.

As we know, in our society, the issue of bankruptcy is very old. In the United States, a Bankruptcy clause (Clause 4 of Section 8 of Article I) was adopted in its Constitution on September 3, 1787 (see Warren (1935), page 5). There might be moral arguments for allowing agents to discharge their debt. However, as the following paragraphs show, debates on bankruptcy bills provide ample economic justifications for such a discharge.

Allowing for repudiation of debt through bankruptcy law can increase economic activity and improve welfare of society. This idea has been in public discussion for at least 200 years. For example, Warren (1935), on page 16, writes the following about the debate on a bankruptcy bill in 1792; "the advocates of the bill, largely from the commercial sections of the country, pointed out the necessity of restoring to active trade-life the thousands of debtors then in jail or else unable to resume business by reason of their load of undischarged debts; and they further urged the necessity of preventing such a condition from again arising." And again on page 18, "As Jefferson wrote to Madison: 'The whole commercial race are lying on their oars and gathering in their affairs, not knowing what new failure may put their resources to the proof.' In the existing stagnation of commerce, he said, loans could not be made or money transferred from one city to another." Using the language of modern economics, we can say that an equilibrium in an economy with bankruptcy can have more asset trade than and strongly pareto dominate an equilibrium in the corresponding economy without bankruptcy.

Similarly, the idea of an optimal bankruptcy law, one that balances rights of a creditor against the misfortune of a debtor, has been in public discussion for at least 200 years. For example, Warren (1935), on page 17, writes the following about the views of James A. Bayard of Delaware in 1792, "A bankrupt law he held was necessary to protect creditors from dishonest and fraudulent debtors, as well as to enable creditors to protect honest debtors whose trade had been subjected to unforeseen accidents who shall surrender all their property in order to obtain a discharge." And again on page 166, he quotes the following objective of a bankruptcy law from the papers of James A. Bayard, "Its object is, in the first place, to support mercantile credit, by protecting the rights of creditors against the fraud of dishonest and the folly of imprudent debtors who may waste or conceal their property while the ordinary forms of law are going on against them; and secondly to 
encourage fair industry and prudent conduct, by enabling honest debtors reduced by misfortune, to give up their property, free themselves entirely from their debts, and begin the world anew, which no man will ever have the courage to do, while a load of old debts is hanging on him." Thus, an optimal credit limit and exemption level depends, among other things, on the characteristics of the agents in the economy. ${ }^{4}$

In economics, there is an extensive literature on bankruptcy. ${ }^{5}$ To model bankruptcy, many economists have used a partial equilibrium framework. Their models provide important insights about optimal debt contracts, about optimal corporate debt versus equity and about dynamic credit cycles. However, these models do not always capture the feedback effects that are captured naturally in the general equilibrium framework. Also, these models and some of the earlier models in the general equilibrium framework exogenously specify whether an economic agent is a debtor or creditor (hence in these models, agents cannot be buyers of some assets and sellers of others) and they do not have any real heterogeneity among the economic agents involved. The reader can get a flavor of some of these models from the papers of Townsend (1979), Stiglitz and Weiss (1981), Aghion and Hermalin (1990), Hart and Moore (1994), Kiyotaki and Moore (1997), Bernanke, Gertler, and Gilchrist (1996), Wang and White (2000). This list is by no means comprehensive.

The first attempts to include bankruptcy in a special model of general equilibrium with complete markets seem to be by Shubik (1972) and Shubik and Wilson (1977). In the framework of a fullblown model of general equilibrium with complete markets, a seminal paper is by Kehoe and Levine (1993). Drawing on the literature on dynamic consistency, Kehoe and Levine introduce individual rationality constraints in the form of endogenous debt limits. These imply that in an equilibrium, no agent defaults in any state. Alvarez and Jermann (2000) (building on Kehoe and Levine (1993) and Kocherlakota (1996)) cast these constraints in the form of portfolio constraints and investigate limited risk-sharing. Their models provide insight in understanding consumption and have been used in the macroeconomics literature. However, by their very construction, these models do not have any default or bankruptcy in equilibrium. Hence, if we believe that default or bankruptcy are ongoing phenomena in market trading and that markets can function smoothly in their presence then these models cannot explain the existence of default or bankruptcy.

The model that I construct belongs to the class of economic models of general equilibrium with

\footnotetext{
${ }^{4}$ For more details on the history of bankruptcy law, the reader can consult Warren (1935) and Dunscomb(Jr.) (1898).

${ }^{5}$ A search in EconLit for bankruptcy yields more than 1200 articles since 1969.
} 
incomplete markets or, GEI-models. ${ }^{6}$ In this framework, a seminal paper is by Dubey, Geanakoplos, and Shubik (1997). Some other models are proposed by Dubey, Geanakoplos, and Zame (1997), Modica, Rustichini, and Tallon (1999) and Araujo and Pascoa (1999). Some of the economic justifications for allowing default and bankruptcy that are mentioned above can be seen formally in these models, in Shubik and Wilson (1977), in Zame (1993) and also in the model I construct. However, (as we shall see below) when compared to these models, my model portrays better the institutions involved in bankruptcy and it allows for an explicit role for exemptions and credit limits. Therefore, in my model, we can see directly the effect of these institutional details on asset trade, debt recovery and equilibrium allocations.

Dubey, Geanakoplos, and Shubik (1997) assume that an agent incurs a loss in utility when he defaults, the loss increasing proportionately in value of default. In their words, utility penalties are "interpreted as the sum of third party punishment, future (unmodelled) reputation losses, and pangs of conscience" (see page 9 of their paper). However, utility penalties exist in the psyche of the consumer. Such penalties leave the creditor no legal recourse for debt recovery, they exclude the role of the legal framework in determining an agent's choice set and they rule out any effect of an agent's default history on his future access to asset markets. Utility penalties, by subsuming these relevant economic processes, prevent any analysis of them. In the model I construct, there are no direct utility penalties. Instead, I work with the more realistic framework of economic and legal processes and their effects on an agent's choice environment.

Also, in a general equilibrium model of bankruptcy, there can be what we may call a trivial equilibrium - an equilibrium in which agents expect economy-wide bankruptcy and no recovery on the assets and hence there is no trade in the assets. As Dubey, Geanakoplos and Shubik point out, with pessimistic expectations about debt recovery, this is a possibly realistic equilibrium. Of course, we also want to know when there is a non-trivial equilibrium. Dubey, Geanakoplos and Shubik show the existence of a non-trivial equilibrium by ruling out the trivial equilibrium. They rule it out by requiring agents to expect full recovery on each asset in which there is no trade (or more precisely, on each asset for which the aggregate value of promised delivery is zero). They motivate this by writing (on page 17), "one can (but need not) interpret these expectations as if the government guaranteed delivery on the first infinitesimal promises". This is certainly possible but might not always be the case, especially when a government is reluctant or unable to credibly guarantee delivery. Also, this expectational refinement is based on an endogenous variable (value

\footnotetext{
${ }^{6}$ For details of the GEI model, see Magill and Quinzii (1996).
} 
of promised delivery) and it rules out the (possibly realistic) trivial equilibrium. I do not make any such expectational refinement, in my model there can be a trivial equilibrium and I show the existence of a non-trivial equilibrium by making assumptions about the exogenous parameters of the model.

Dubey, Geanakoplos, and Zame (1997) require the seller of an asset to purchase collateral which can be confiscated if he defaults. To operationalize this, Dubey, Geanakoplos and Zame treat all goods as durable. At the time of delivery, if an agent defaults he loses the undepreciated portion of the collateral. The penalty of losing the undepreciated value of collateral is economic in nature and therefore, it avoids the difficulties of utility penalties. However, the model of Dubey, Geanakoplos and Zame omits an important aspect of default. In their model an agent is never bankrupt. This is because in their model, the amount that an agent has to repay on his debt is never greater than the value of the undepreciated collateral. (This also implies that debt recovery from an agent on one claim is insensitive to an agent's exposure to other claims.) The creditor has no legal recourse over and above this value if this value is less than the value of the promised payoff. Since an agent has to purchase collateral when he sells an asset, he always has enough resources to repay his debt. Hence, he is never bankrupt. In the model I construct, there is bankruptcy. Moreover, I show that we can have bankruptcy without invoking the apparatus of durable goods or securing lending by an already identified portion of an agent's income.

Modica, Rustichini, and Tallon (1999) assume that an agent is aware of the existence of some states of the world and unaware of others. Each agent plans only for states of which he is aware and in such a state his plan accounts for full payment on all his debts. If a state occurs of which an agent is unaware and in this state he has enough resources to repay his debts, he repays his debts fully. Otherwise he defaults. Since different agents might be unaware of different states, an agent expects partial repayment on his holdings of assets even in states of which he is aware.

Modica, Rustichini and Tallon assume that in a state of which an agent is unaware, the maximum penalty for default that a court imposes on him is his income in that state. In a state of which an agent is aware, they say that an agent repays his debt because "a court could impose large penalties if it discovered that the agent is bankrupt" (page 261). Suppose this penalty is the same as the one in a state of which he is unaware. Modica, Rustichini and Tallon assume that the preference of every agent is strongly monotone and convex. In addition, suppose there is one agent who has a bounded intertemporal rate of substitution. In this case if the price of any asset is positive this agent wants to sell an infinite amount of the asset. Therefore, for asset markets to clear it 
is necessary that the price of every asset is zero, which essentially means that asset markets shut down. Thus, in any equilibrium of such an economy, if the price of any asset is to be positive it must be that the penalty which a court imposes in a state of which an agent is aware is larger than the one it imposes in a state of which he is unaware. This implies that a court is cognizant of which states an agent is aware or unaware. Such cognizance is implausible because the notion of an agent's subjective state space is intrinsic to the agent. Thus, in an important sub-collection of economies represented by their model there seems to be an interpretive difficulty.

Modica, Rustichini and Tallon also mention some unusual features of their model. For example, equilibrium with unawareness might not exist even with complete markets. And, it is not possible to interpret their model as one in which agents assign zero probability to states of which they are unaware (page 265).

Araujo and Pascoa (1999) propose a model that is close in spirit to the one that I construct. However, they assume that there is a fraction such that this fraction of every agent's income cannot be garnished by creditors. This implies that the level of exemption of a rich agent can be substantially larger than that of a poor agent. This violates the essence of discharge, exemption and fresh start in bankruptcy law (that is, in exchange for forfeiting his resources in excess of some bare minimum exemption, an agent can discharge his debt and start his commercial life afresh) and it differs from the fixed level of exemption that we actually observe. (With a fixed level of exemption it can be that a very small fraction of the endowment of a poor individual is garnished and a large fraction of the endowment of a rich individual is garnished.) The model that I construct captures this aspect of an exemption. Araujo and Pascoa also assume that assets have nominal payoffs whereas in the model that I construct, assets have real payoffs.

The models by Dubey, Geanakoplos and Shubik, by Dubey, Geanakoplos and Zame, by Modica, Rustichini and Tallon, and by Araujo and Pascoa all fail to capture an important aspect of default - the effect of an agent's default history on his future trading opportunity. This is because their models have only two time periods whereas the earliest such an effect can be captured is in the third period. The model I construct has finitely many periods. In it, the default history of an agent can affect his future trading opportunity in a fairly general manner.

In constructing this model and in proving existence of an equilibrium, I strive to maintain as much flavor of the Arrow-Debreu model as I can. However, the reader will find the following features specific to this model and to the proof I present.

In this model, in any period and state of the world, if the excess of an agent's (gross) income 
over the value of his exemption is less than what he owes, the only penalty imposed on him in that period and state is forfeiture of this excess income. Because his liability is limited to this excess income, an agent might want to sell an infinite amount of an asset. To prevent this, I introduce the notion of a credit limit. Also, in the model, the definition of disposable income implies that the budget set of an agent can be non-convex. To guarantee that aggregate demand is convex-valued, I assume that the model has a continuum of agents and their distribution is atomless.

In the proof of existence of an equilibrium, in addition to an agent's optimal choice of a consumption and portfolio plan, it is important to know the loss and debt information associated with this plan. I extend the demand set to include this information. Also, in the proof, it is necessary to have a procedure to compute the default rate from aggregate loss and aggregate debt. I define a default rate correspondence to carry out this computation. Both these modifications can jeopardize a naive adoption of a standard proof of existence of an equilibrium (for example, as given in Hildenbrand (1974)). Part of what I show in this paper is that a careful adoption of a standard proof of existence of an equilibrium is possible even with these modifications. This shows that in the existence proof in this paper, we may use intuition similar to that used in a standard proof of existence of an equilibrium. It also shows the power and adaptability of the standard proof.

To formalize and prove the claims mentioned above, I proceed in the following manner. First, I specify the model, define an economy and an equilibrium in it and state the main results. Then, I present some welfare effects of bankruptcy. After that, I prove the main results. Finally, I point out some ways in which we may modify and extend the model.

\section{Specification of the Model}

To specify the model, I proceed in the following manner. First, I outline the organization of economic activity in an exchange economy in which there is bankruptcy. This helps us understand the role of the relevant economic and legal entities and the relations among them. Then, I formally introduce some basic concepts. After that, abstracting some components from the existing legal framework, I formalize the rights of creditors and debtors in the model. This helps us determine the financial position of an agent in the model. After that, from some trading restrictions that we observe, I derive a credit limit for an agent in the model. This helps us formalize the role of credit limits in the model. Finally, I define a budget set, a demand set, an economy and an equilibrium in an economy and state the main results. 
At an elementary level, an individual becomes bankrupt if his choice set includes plans which entail his becoming bankrupt in some states of the world and he chooses such a plan. His choice set might include such plans because of uncertainty and the legal framework. Uncertainty (about his ability to honor promises of future delivery of goods) enables an agent to make promises of future delivery of goods which, in some states, exceed his ability to honor them. The legal framework allows him, in some situations, to renege on his promise and in the provisions of bankruptcy law, seek protection from creditors. Thus, there is personal bankruptcy because uncertainty combined with the institutional framework allows plans which entail bankruptcy in some states of the world to be included in an individual's choice environment and he chooses such a plan.

In an exchange economy in which there is bankruptcy, economic activity might be organized as follows. There are consumption goods and assets. Agents use assets to move income among different time periods and among different states of the world so that they can finance the bundle of consumption goods that they desire most. One way to move future income to the present is by getting a loan. This is like selling a promise for future delivery of some good.

When an agent goes to a bank or a credit institution to get a loan, the lenders never determine his actual ability to repay the loan in every possible state of the world. Rather, they estimate this ability. They estimate the agent's future salary, confirm his employment status, evaluate his default history and determine the riskiness of the loan by considering repayment schedules on similar loans to others. Using standardized criteria they determine an agent's credit limit. An agent can get a loan up to his credit limit. In this view, a bank or a credit institution serves mainly as a check-point that imposes a credit limit constraint on an agent if he wants to sell a promise for future delivery of some good. As long as an agent's promise for future delivery satisfies the constraint imposed by this check-point, he may sell such promises.

The lenders aggregate these loans to manufacture a composite security, pieces of which are traded in asset markets. ${ }^{7}$ An agent purchasing a unit of this asset gets a slice of the underlying loans and bears the average default risk on them. ${ }^{8}$

At the time of repayment, creditors have some claim to a debtor's income. However, to ensure that the debtor is not left penniless, bankruptcy law provides for some exemptions. ${ }^{9}$ A debtor's

\footnotetext{
${ }^{7}$ For example, markets in which collateralized mortgage obligations are traded, markets in which credit card debt is traded and markets in which car loans are traded.

${ }^{8}$ In thinking about securitized pools of assets, I follow Dubey, Geanakoplos, and Shubik (1997).

${ }^{9}$ See $\S 522$ of Title 11 of the United States Code Annotated. Examples of exemptions are (some of the) value of homes, vehicles, retirement accounts, furniture, clothes and other personal property. White (1998) lists exemptions
} 
income up to the value of these exemptions is exempted from forfeiture even if he has debt outstanding (an abstraction of $\S 522(\mathrm{~b})(1)$ of Title 11 of the United States Code Annotated). Although creditors cannot reach into a debtor's exemptions to recover their money they have a prior claim to the excess of a debtor's income over the value of his exemptions (abstraction of $§ 726$ ). If an agent's (gross) income minus his exemptions is sufficient to repay his creditors, he is required by law to pay his debts fully. From such an agent there is no loss on any asset and his disposable income is what remains of his income after paying off what he owes. If an agent's (gross) income minus his exemptions is insufficient to repay his creditors, he is bankrupt. From every bankrupt agent the courts confiscate the excess of his income over his exemptions, determine the loss from him on each asset based on the method of proportional recovery and discharge his debts (abstractions of $\S 704$, $\S 726-727)$. The disposable income of each bankrupt agent is the value of his exemptions. ${ }^{10}$

Agents use their disposable income to finance their consumption. Total loss on an asset is the aggregate of loss from each agent on this asset. The ratio of total loss on an asset to total debt owed on it is the default rate on the asset. Creditors bear the loss in proportion to their asset holdings.

The model of an exchange economy that I construct has the essential features mentioned above. A natural notion of equilibrium in such an economy is a collection of prices, default rates and individual plans such that individuals are optimizing, markets are clearing and the default rate on an asset equals the ratio of total loss on that asset to total debt owed on it. With this notion of equilibrium and using standard assumptions about preferences and endowments and using natural assumptions about the rights of creditors and debtors and about credit limits, I show that every economy represented by this model has an equilibrium.

Let us look at some basic concepts. I assume that partial order on $R^{K}, K=1,2, \ldots$, is the usual one. ${ }^{11}$ For any $\xi \in R^{K}, \xi_{+}$denotes the positive part of $\xi$ and is the vector with $k$-th component $\xi_{k}$ if $\xi_{k} \geq 0$ and 0 otherwise and $\xi_{-}$denotes the negative part of $\xi$ and is the vector with $k$-th by state for each state in the United States and for the District of Columbia. Note that, by $\S 522(\mathrm{e})$, a debtor cannot contract away his exemptions. As Epstein (1995) writes on page 177, such a contract is not enforceable.

${ }^{10}$ The model that I construct abstracts some essential components of bankruptcy under Chapter 7 of the United States Bankruptcy Code. According to the Administrative Office of the U.S. Courts (News Release; June 9, 2000), in the last six years, Chapter 7 bankruptcies hovered around $73 \%$ of all personal bankruptcies and personal bankruptcies increased from $94 \%$ to $97 \%$ of all bankruptcies. A description of the Bankruptcy Code is given in Epstein (1995) and a quick overview in White (1998).

${ }^{11} x \geq y$ means $x_{k} \geq y_{k}, k=1, \ldots, K ; x>y$ means $x \geq y$ and $x \neq y ; x \gg y$ means $x_{k}>y_{k}, k=1, \ldots, K$. For $E \subset R^{K}, E_{+}$is the set of those elements in $E$ which are greater than or equal to 0 . 
component $-\xi_{k}$ if $\xi_{k} \leq 0$ and 0 otherwise. Thus, for any $\xi \in R^{K}, \xi_{+} \geq 0, \xi_{-} \geq 0$ and $\xi=\xi_{+}-\xi_{-}$.

The model has a finite number of periods, indexed $t=1, \ldots, T$ and a finite number of states, indexed $s=1, \ldots, S$. Each state $s$ is a particular history of the environment from period 1 through period $T$. The events observable in period $t$ are given by a partition $\mathcal{S}_{t}$ of $\{1, \ldots, S\}$. To reflect dependence of actions in period $t$ on events observable in that period, I shall say that a function on $\{1, \ldots, S\}$ is $\mathcal{S}_{t}$-measurable if it is constant on each event $E_{t} \in \mathcal{S}_{t}$. To reflect the additional availability of information as time goes on, I assume that the sequence of partitions, $\mathcal{S}=\left(\mathcal{S}_{t}\right)_{t=1}^{T}$, is nondecreasing in fineness and call it an information structure. For $t=1, \ldots, T$, let $\mathcal{R}_{t}=\left\{\left(\xi_{t}(s)\right)_{s=1}^{S} \in R^{S} \mid \xi_{t}(\cdot)\right.$ is $\mathcal{S}_{t}$-measurable $\}$ be the subspace of $R^{S}$ consisting of vectors which are $\mathcal{S}_{t}$-measurable and let $\mathcal{R}=\underset{t=1}{T} \mathcal{R}_{t}$.

The model has a finite number of consumption goods, indexed $\ell=1, \ldots, L$. The consumption space in period $t$ is $X_{t}=\left(\mathcal{R}_{t}^{L}\right)_{+}$and the consumption space is $X=\underset{t=1}{\underset{\times}{\times}} X_{t}$. An element $x=$ $\left(x_{t}\right)_{t=1}^{T} \in X$ is a consumption plan which entails consumption of $x_{t}(s)_{\ell}$ units of good $\ell$ in period $t$, state $s$.

The model has a finite number of assets or contracts, ${ }^{12}$ indexed $j=1, \ldots, J$. Their payoff in period $t$ is summarized by a $S \times J$ matrix of asset returns, denoted $A_{t}$. Its $s j$-th component, denoted $A_{t}(s)_{j}$, specifies the (non-negative) payoff of asset $j$ in period $t$, state $s$ in terms of good $\ell=1$. For convenience, I assume that $A_{1}$ is the zero matrix and to reflect the dependence of asset returns on the information available, I assume that for each $t \geq 2, A_{t}(\cdot)$ is $\mathcal{S}_{t}$-measurable. The sequence of asset return matrices, $A=\left(A_{t}\right)_{t=1}^{T}$, is called an asset structure. Portfolios of assets are defined as follows. The portfolio space in period $t \leq T-1$ is $Z_{t}=\mathcal{R}_{t}^{J}$ and that in period $t=T$ is $Z_{T}=\{0\} \subset \mathcal{R}_{T}^{J}$. The portfolio space is $Z=\underset{t=1}{\underset{T}{\times}} Z_{t}$. An element $z=\left(z_{t}\right)_{t=1}^{T} \in Z$ is a portfolio plan which entails a holding of $z_{t}(s)_{j}$ units of asset $j$ in period $t$, state $s$. Occasionally, we shall run across the notation $z_{t-1}$, where $t=1$. Whenever we have to consider a portfolio $z_{0}$, let us use $z_{0}=0$.

Prices of goods and assets are defined as follows. The price space in period $t \leq T-1$ is $\Delta_{t}=\left\{\left(p_{t}, q_{t}\right) \in\left(\mathcal{R}_{t}^{L+J}\right)_{+} \mid\right.$for every $\left.s, \sum_{\ell} p_{t}(s)_{\ell}+\sum_{j} q_{t}(s)_{j}=1\right\}$ and that in period $t=T$ is $\Delta_{T}=\left\{\left(p_{T}, 0\right) \in\left(\mathcal{R}_{T}^{L+J}\right)_{+} \mid\right.$for every $\left.s, \sum_{\ell} p_{T}(s)_{\ell}=1\right\}$. The price space is $\Delta=\underset{t=1}{\stackrel{T}{\times}} \Delta_{t}$. Each element $(p, q) \in \Delta$ is a price system with $p_{t}(s)_{\ell}$ the price of a unit of good $\ell$ in period $t$, state $s$

\footnotetext{
${ }^{12}$ In this model, assets have long lives. However, it is easy to incorporate in this model assets with short lives. In fact, if there are only assets with short lives, it is easier to prove some components of the proof of existence of an equilibrium. Also, all welfare effects given in this paper remain true even if assets have short lives.
} 
and $q_{t}(s)_{j}$ the price of a unit of asset $j$ in period $t$, state $s$.

The model has a continuum of agents $I=[0,1]$, indexed $i \in I .(I, \mathcal{B}, \mu)$ is a measure space with $\mu$ a complete, finite, atomless measure. Each agent $i$ has a preference relation, $\succeq^{i} \subset X \times X$, which is complete, reflexive, transitive, convex, continuous and strongly monotone $\left(x>\dot{x} \Rightarrow x \succ^{i} \dot{x}\right)^{13}$ and an endowment, $w^{i}=\left(w_{t}^{i}\right)_{t=1}^{T} \in X$. I assume that the collection of endowments, $\left(w^{i}\right)_{i \in I}$, lies in a bounded set, it satisfies $\inf _{i} w^{i} \gg 0$ and that the map $i \mapsto\left(\succeq^{i}, w^{i}\right)$ is measurable.

These are the basic concepts. Let us now look at the rights of creditors and debtors in the model and use these to determine the financial position of an agent.

We know that there are laws governing priority of claims of creditors on a debtor's income and laws protecting debtors from the claims of creditors. Abstracting some components from this legal framework, I assume the following about the decision making environment of an agent in the model. (1) There is an exemption - that is, a bundle of goods such that the value of an agent's endowment up to the value of this bundle is exempted from forfeiture even if he has debts outstanding, (2) a creditor has a prior claim to the excess of a debtor's income over the value of the debtor's exemption and (3) the claim of any creditor on an agent's income has the same priority as the claim of any other creditor. These assumptions describe the rights of creditors and debtors in the model. ${ }^{14}$ The first assumption implies that the exemption value of an agent is the lesser of the value of his endowment and the value of the exemption bundle. The second assumption implies that if the liquidation value of an agent - that is, the excess of his (gross) income over his exemption value - is greater than the debt he owes, his liability is the debt he owes. Otherwise, his liability is his liquidation value. The third assumption implies that creditors share losses from a debtor in proportion to what he owes them. If we think of unsecured lending as lending which is not secured by an already identified portion of future income but only by a general claim on it then this model has only unsecured lending. ${ }^{15}$

To see an illustration of the notion of a default rate on an asset, suppose that total loss from agents on this asset is $\beta$ and total debt owed by them on this asset is $\gamma$, with $0 \leq \beta \leq \gamma$ and $\gamma>0$. Then, the default rate on this asset is $\alpha=\frac{\beta}{\gamma}$ and recovery rate $1-\alpha$. Thus, default rate on an asset in a particular period and state is a number between 0 and 1 telling us the proportion of debt which is bad. This motivates the following notation.

\footnotetext{
${ }^{13}$ The notions of indifference $\left(\sim^{i}\right)$ and strict preference $\left(\succ^{i}\right)$ are the usual ones.

${ }^{14} \mathrm{~A}$ limitation of this model is that it does not allow for renegotiation.

${ }^{15}$ We can interpret an asset in this model as a reduced form representation of the unsecured portion of an underlying asset but I shall not force this interpretation.
} 
The default rate space in period $t=1$ is $\nabla_{1}=\{0\} \subset \mathcal{R}_{1}$ and in period $t \geq 2$ is $\nabla_{t}=$ $\left\{\alpha_{t} \in \mathcal{R}_{t}^{J} \mid 0 \leq \alpha_{t} \leq 1\right\}$. (Here, 0 is the vector of zeros and 1 the vector of ones, both in $\mathcal{R}_{t}^{J}$.) The default rate space is $\nabla=\underset{t=1}{\stackrel{T}{\times}} \nabla_{t}$. An element $\alpha \in \nabla$ is a default rate system with $\alpha_{t}(s)_{j}$ the default rate on asset $j$ in period $t$, state $s$.

To ensure that in each period and state the value of the exemption is not zero, I assume that an exemption is an element $e \in X$ such that $e \gg 0$.

Let us now determine the financial position of an agent. Suppose $(p, q, \alpha)$ is a price and default rate system and $z^{i}$ a portfolio plan for agent $i$. In period $t$, state $s$, agent $i$ 's endowment income is $p_{t}(s) w_{t}^{i}(s)$, he is supposed to receive $p_{t}(s)_{1}\left[A_{t}(s)+q_{t}(s)\right] z_{t-1}^{i}(s)_{+}$from his period $t-1$ asset purchases but expects to receive only $\sum_{j=1}^{J}\left(1-\alpha_{t}(s)_{j}\right) p_{t}(s)_{1}\left[A_{t}(s)_{j}+q_{t}(s)_{j}\right]\left(z_{t-1}^{i}(s)_{+}\right)_{j}$ and he owes $p_{t}(s)_{1}\left[A_{t}(s)+q_{t}(s)\right] z_{t-1}^{i}(s)_{-}$. The gross income of agent $i$ in period $t$, state $s$ is the sum of his endowment income and what he expects to receive in that period and state. His exemption value in that period and state is $\epsilon^{i}\left(p, q, \alpha, z^{i}\right)_{t}(s)=\min \left(p_{t}(s) w_{t}^{i}(s), p_{t}(s) e_{t}(s)\right)$ and his liquidation value in that period and state is the excess of his gross income over his exemption value. Agent $i$ is bankrupt in period $t$, state $s$ if in that period and state his liquidation value is less than what he owes. His liability in period $t$, state $s$ is the lesser of his liquidation value in that period and state and what he owes in it. An implication of these definitions is that if we think of default as a situation in which an agent repays less than what he owes then, in this model, an agent defaults exactly when he is bankrupt. ${ }^{16}$ The net income of agent $i$ in period $t$, state $s$ is

$$
\begin{aligned}
f^{i}\left(p, q, \alpha, z^{i}\right)_{t}(s)= & p_{t}(s) w_{t}^{i}(s)+\sum_{j}\left(1-\alpha_{t}(s)_{j}\right) p_{t}(s)_{1}\left[A_{t}(s)_{j}+q_{t}(s)_{j}\right]\left(z_{t-1}^{i}(s)_{+}\right)_{j} \\
& -p_{t}(s)_{1}\left[A_{t}(s)+q_{t}(s)\right] z_{t-1}^{i}(s)_{-} .
\end{aligned}
$$

For $t=1$ this reduces to $p_{1}(s) w_{1}^{i}(s)$. The disposable income of agent $i$ in period $t$, state $s$ is

$$
W^{i}\left(p, q, \alpha, z^{i}\right)_{t}(s)=\max \left(f^{i}\left(p, q, \alpha, z^{i}\right)_{t}(s), \epsilon^{i}\left(p, q, \alpha, z^{i}\right)_{t}(s)\right)
$$

For $t=1$ this reduces to $p_{1}(s) w_{1}^{i}(s)$. It is trivial to check that agent $i$ is bankrupt in period $t$, state $s$ if and only if $f^{i}\left(p, q, \alpha, z^{i}\right)_{t}(s)<\epsilon^{i}\left(p, q, \alpha, z^{i}\right)_{t}(s)$. In this case his disposable income is $\epsilon^{i}\left(p, q, \alpha, z^{i}\right)_{t}(s)$ and he contributes $(\epsilon-f)^{i}\left(p, q, \alpha, z^{i}\right)_{t}(s)=\epsilon^{i}\left(p, q, \alpha, z^{i}\right)_{t}(s)-f^{i}\left(p, q, \alpha, z^{i}\right)_{t}(s)$ to the pool of bad debts. Otherwise, he contributes nothing to the pool of bad debts. The loss from agent $i$ in period $t$, state $s$ is $\lambda^{i}\left(p, q, \alpha, z^{i}\right)_{t}(s)=\max \left((\epsilon-f)^{i}\left(p, q, \alpha, z^{i}\right)_{t}(s), 0\right)$. The debt owed by agent $i$ on asset $j$ in period $t$, state $s$ is $\gamma^{i}\left(p, q, \alpha, z^{i}\right)_{t}(s)_{j}=p_{t}(s)_{1}\left[A_{t}(s)_{j}+q_{t}(s)_{j}\right]\left(z_{t-1}^{i}(s)_{-}\right)_{j}$.

\footnotetext{
${ }^{16}$ This does not mean that he has no choice about whether to default or not. He still controls his portfolio choice which affects his bankruptcy status and hence his default status.
} 
The ratio of loss from agent $i$ in a period and state to what he owes in it is the proportion of his debt that creditors cannot recover. Therefore, the loss from agent $i$ on asset $j$ is this proportion of what he owes on asset $j$. Formally, the loss from agent $i$ on asset $j$ in period $t$, state $s$ is $\beta^{i}\left(p, q, \alpha, z^{i}\right)_{t}(s)_{j}= \begin{cases}\frac{\lambda^{i}\left(p, q, \alpha, z^{i}\right)_{t}(s)}{p_{t}(s)_{1}\left[A_{t}(s)+q_{t}(s)\right] z_{t-1}^{i}(s)_{-}} \gamma^{i}\left(p, q, \alpha, z^{i}\right)_{t}(s)_{j} & \text { if } p_{t}(s)_{1}\left[A_{t}(s)+q_{t}(s)\right] z_{t-1}^{i}(s)_{-}>0 \\ 0 & \text { otherwise. }\end{cases}$ Notice that for $t=1, \beta^{i}\left(p, q, \alpha, z^{i}\right)_{1}(s)_{j}=\gamma^{i}\left(p, q, \alpha, z^{i}\right)_{1}(s)_{j}=0$.

This summarizes the financial position of an agent in the model. Let us now look at trading restrictions and how these limit the ability of an agent to take on debt.

From a practical point of view, we know that an individual's ability to sell an asset and take on debt is restricted by some credit limit. In the model, a bound on an agent's ability to sell an asset is important because with a positive asset price, debt obligation limited by exemption value and no bound on asset sales, there are many cases in which an agent wants to sell an infinite amount of the asset. ${ }^{17}$ Therefore, for asset markets to clear it is necessary that the price of every asset be zero, which essentially means that asset markets shut down. A credit limit implies a bound on asset sales. It is this property of a credit limit that I want to abstract and formalize.

We know that a credit limit which an individual faces depends, among other things, on an estimate of his ability to deliver the goods, on his default history and on the price of the asset. ${ }^{18}$ In the model, this is formalized in the following definition.

Let $Q=\left\{q \in \mathcal{R}_{+}^{J} \mid\right.$ there is $p \in \mathcal{R}_{+}^{L}$ and $\left.(p, q) \in \Delta\right\}$ and for every $j, s, t$ with $t \leq T-1$, let $Q_{t}(s)_{j}=\left\{q \in Q \mid q_{t}(s)_{j} \geq \frac{1}{2 J}\right\}$. A credit limit for agent $i$ is a continuous function $C^{i}: Q \times \mathcal{R}_{+}^{J} \rightarrow$ $\mathcal{R}_{+}^{J}$ (mapping $(q, \beta)$ to $\left.C^{i}(q, \beta)\right)$ that is weakly decreasing in $\beta .{ }^{19}$ To reflect the dependence of a credit limit on the information available in a particular period, I assume that for every $t, C^{i}(q, \beta)_{t}$ depends only on $q_{t^{\prime}}$ and $\beta_{t^{\prime}}$ where $t^{\prime} \leq t$. A credit limit system is a map $C: i \mapsto C^{i}$. I assume that this map is measurable, ${ }^{20}$ that $C^{i}$ evaluated at $\beta=0$ when viewed as a function of $i$ and $q$ is bounded and that for every $j, s, t$ with $t \leq T-1, \mu\left(\left\{i \in I \mid \inf _{q \in Q_{t}(s)_{j}, \beta \in \mathcal{R}_{+}^{J}} C^{i}(q, \beta)_{t}(s)_{j}>0\right\}\right)>0$ and if $q_{t}(s)_{j}=0$ then $\mu\left(\left\{i \in I \mid C^{i}(q, 0)_{t}(s)_{j}=0\right\}\right)=\mu(I)$.

The last two assumptions are useful in proving the main results in this paper. We can think

\footnotetext{
${ }^{17}$ For example, every agent with strongly monotone and convex preferences who has a bounded intertemporal rate of substitution wants to sell an infinite amount of the asset.

${ }^{18}$ The price of an asset will reflect the riskiness of the asset.

$\left.{ }^{19} \beta \leq \dot{\beta} \Rightarrow C^{i}(\cdot, \dot{\beta}) \leq C^{i}(\cdot, \beta)\right)$.

${ }^{20}$ The target space is, of course, the space of closed subsets of $Q \times \mathcal{R}_{+}^{J} \times \mathcal{R}_{+}^{J}$ along with the sigma-algebra generated
} by the topology of closed convergence. 
of these assumptions in the following manner. The last assumption says that if in a particular period and state, the price of an asset is zero then, regardless of his default history, almost no agent can sell this asset. Of course, if the price of an asset is zero and if an agent selling this asset has to deliver something on this asset he will choose not to sell the asset and this assumption is superfluous. This assumption is useful in the case when, even though the price of an asset is zero, an agent is indifferent between selling or not selling the asset. This happens if the agent is not required to deliver anything on the asset or if he is bankrupt in the next period. In this situation the last assumption implies that the agent does not sell the asset.

The assumption before the last one says that, in a particular period and state, if the price of an asset is bounded away from zero then there are some agents who, regardless of their default history, can sell this asset. This captures the idea that a credit limit for an agent looks not just to the past but also to the future. It looks to the future in the sense that there are some agents who, even though they have a bad default history, will have some money in the next period and hence are allowed to undertake some promises of future delivery.

In this model, I assume that a credit limit system is exogenous. It would be more satisfying to endogenize this by postulating an abstract credit limit agency which determines the credit limit of an agent as the result of an optimization procedure. At the very least, we might expect this procedure to assign a smaller credit limit to an agent when (expected) loss from this agent is higher in future periods. However, as an example given below shows, creditors might prefer debtors to have more debt even when they expect debtors to cause them greater (expected) losses in the future. This shows us that the notion of an optimal credit limit depends on the characteristics of agents. Keeping credit limits exogenous allows us to see the effect of different credit limits on equilibrium outcomes. In future work, I plan to use this information to investigate different methods of endogenizing credit limits.

Also, in the model, I assume that agents can have individualized credit limits. This does not mean that agents lose their trading anonymity. At most, they lose their anonymity to a creditsetting financial intermediary like a bank, a brokerage house or some other lending institution. Just like they lose their anonymity to a settlement system which allocates a bankrupt agent's income among his creditors. In my model (and to an extent in the other models mentioned above) these intermediaries are abstracted away because they are assumed to play a passive and standardized role in the economy. This allows us to focus on the trading and allocation aspects of competitive markets. Once credit limits for agents are determined (intuitively, by financial intermediaries using 
standardized criteria in a passive manner) and a settlement system is in place, these agents can trade anonymously through markets.

Of course, it is easy and obvious to see that my model can be modified so that credit limits are independent of agents. This also implies that in determining a credit limit for an agent, we use some measure of loss independent of particular agents (for example, we can use aggregate loss). Slightly more generally, depending on some characteristics of agents, we can partition the agents into a few classes and for agents in each class, use their aggregate loss to determine their credit limit. To see some other modifications and extensions of this model, see the last section of this paper.

Using the definition of a credit limit, I formalize the notion that an agent sells assets subject to a check-point authorization in the following definition of admissibility of a portfolio plan. Let $(p, q, \alpha)$ be a price and default rate system and $C^{i}$ a credit limit for agent $i$. A portfolio plan $z^{i}$ is $\left(C^{i}, p, q, \alpha\right)$ - admissible if for every $j, s, t$ with $t \leq T-1$,

if there is $s^{\prime} \in E_{t}(s)$ with $A_{t+1}\left(s^{\prime}\right)_{j}>0$, then $A_{t+1}(s)_{j}\left(z_{t}^{i}(s)_{-}\right)_{j} \leq C^{i}\left(q, \beta^{i}\left(p, q, \alpha, z^{i}\right)\right)_{t}(s)_{j}$, otherwise $\left(z_{t}^{i}(s)_{-}\right)_{j} \leq C^{i}\left(q, \beta^{i}\left(p, q, \alpha, z^{i}\right)\right)_{t}(s)_{j}$.

Here, $E_{t}(s)$ is the event in $\mathcal{S}_{t}$ which contains $s$ and $\beta^{i}\left(p, q, \alpha, z^{i}\right)$ is the profile of loss from agent $i$ on every asset in every period and state. The concept of admissibility formalizes the idea that an agent's ability to take on debt depends, among other things, on an agent-specific component which includes his default history and on the price of the asset which reflects the riskiness of the asset. Using portfolio admissibility, a bound on asset sales follows immediately.

Lemma 1. Let $C$ be a credit limit system. Then there is $\hat{z} \in Z$ such that for every price and default rate system $(p, q, \alpha)$, every agent $i$, every $\left(C^{i}, p, q, \alpha\right)$-admissible $z^{i}$, every period $t \leq T-1$, state $s$ and asset $j,\left(z_{t}^{i}(s)_{-}\right)_{j} \leq \hat{z}_{t}(s)_{j}$.

Proof. Let $\hat{z}$ be given by $\hat{z}_{t}(s)_{j}=\frac{\sup _{i, q} C^{i}(q, 0)_{t}(s)_{j}}{\max \left\{A_{t+1}\left(s^{\prime}\right)_{j} \mid s^{\prime} \in E_{t}(s)\right\}}$ if there is $s^{\prime} \in E_{t}(s)$ such that $A_{t+1}\left(s^{\prime}\right)_{j}>$ 0 and $\hat{z}_{t}(s)_{j}=\sup _{i, q} C^{i}(q, 0)_{t}(s)_{j}$ otherwise. Suppose $(p, q, \alpha), i$, and $z^{i}$ are as in the hypothesis. Fix $j, s$ and $t \leq T-1$ arbitrarily. If for every $s^{\prime} \in E_{t}(s), A_{t+1}\left(s^{\prime}\right)_{j}=0$ then $\left(z_{t}^{i}(s)_{-}\right)_{j}$ obviously satisfies the desired inequality. Otherwise, let $\hat{s} \in E_{t}(s)$ be such that $A_{t+1}(\hat{s})_{j}=$ $\max \left\{A_{t+1}\left(s^{\prime}\right)_{j} \mid s^{\prime} \in E_{t}(s)\right\}$. Then, since $z_{t}^{i}(\cdot)$ and $C^{i}(q, 0)_{t}(\cdot)$ are $\mathcal{S}_{t}$-measurable and since $E_{t}(\hat{s})=$ $E_{t}(s)$, we have

$$
A_{t+1}(\hat{s})_{j}\left(z_{t}^{i}(s)_{-}\right)_{j}=A_{t+1}(\hat{s})_{j}\left(z_{t}^{i}(\hat{s})_{-}\right)_{j} \leq C^{i}(q, 0)_{t}(\hat{s})_{j}=C^{i}(q, 0)_{t}(s)_{j}
$$


from which the desired conclusion follows.

We can now easily comprehend what a budget set for an agent will be like in this model. An agent's budget set consists of all consumption and (admissible) portfolio plans which are affordable. His demand set consists of those plans in the budget set which are optimal with respect to his preference relation. Formally, let $C$ be a credit limit system and $(p, q, \alpha)$ a price and default rate system. For an agent $i$, a consumption and portfolio plan $\left(x^{i}, z^{i}\right)$ is $(p, q, \alpha)$-affordable if in every period $t$ and state $s, p_{t}(s) x_{t}^{i}(s)+q_{t}(s) z_{t}^{i}(s) \leq W^{i}\left(p, q, \alpha, z^{i}\right)_{t}(s)$. It is strictly affordable if the inequality is strict. The budget set for agent $i$ is

$$
B^{i}(p, q, \alpha)=\left\{\left(x^{i}, z^{i}\right) \in X \times Z \mid\left(x^{i}, z^{i}\right) \text { is }(p, q, \alpha) \text {-affordable and } z^{i} \text { is }\left(C^{i}, p, q, \alpha\right) \text {-admissible }\right\} \text {. }
$$

The demand set for agent $i$ is

$$
D^{i}(p, q, \alpha)=\left\{\left(x^{i}, z^{i}\right) \in B^{i}(p, q, \alpha) \mid\left(\dot{x}^{i}, \dot{z}^{i}\right) \in B^{i}(p, q, \alpha) \Rightarrow x^{i} \succeq^{i} \dot{x}^{i}\right\}
$$

It is easy to see that $B^{i}(p, q, \alpha)$ is compact if and only if $p \gg 0$ and $q_{t} \gg 0$ (for $t \leq T-1$ ); if $B^{i}(p, q, \alpha)$ is compact then $D^{i}(p, q, \alpha)$ is not empty; and if $D^{i}(p, q, \alpha)$ is not empty then $p \gg 0$. It is also easy to see that the definition of disposable income implies that the budget set can be non-convex. ${ }^{21}$

We now have all the components to define an economy and an equilibrium in it. An economy represented by this model is a collection

$$
\left\{\mathcal{S}, A,\left(\succeq^{i}, w^{i}\right)_{i \in I}, e, C\right\}
$$

where $\mathcal{S}=\left(\mathcal{S}_{t}\right)_{t=1}^{T}$ is an information structure, $A=\left(A_{t}\right)_{t=1}^{T}$ is an asset structure, $\left(\succeq^{i}, w^{i}\right)$ is the preference relation and endowment of agent $i, e$ is an exemption, and $C$ is a credit limit system. An equilibrium in an economy is a collection $\left(p, q, \alpha ;\left(x^{i}, z^{i}\right)_{i \in I}\right)$ where $(p, q, \alpha)$ is a price and default rate system and

- for almost every $i \in I, \quad\left(x^{i}, z^{i}\right) \in D^{i}(p, q, \alpha)$,

- for every $s, t, \quad \int_{I} x_{t}^{i}(s) d i=\int_{I} w_{t}^{i}(s) d i \quad$ and $\quad \int_{I} z_{t}^{i}(s) d i=0$,

- for every $j, s$ and every $t \geq 2, \quad \alpha_{t}(s)_{j} \in \begin{cases}\left\{\frac{\int_{I} \beta^{i}\left(p, q, \alpha, z^{i}\right)_{t}(s)_{j} d i}{\int_{I} \gamma^{i}\left(p, q, \alpha, z^{i}\right)_{t}(s)_{j} d i}\right\} & \text { if } \int_{I} \gamma^{i}\left(p, q, \alpha, z^{i}\right)_{t}(s)_{j} d i>0 \\ {[0,1]} & \text { if } \int_{I} \gamma^{i}\left(p, q, \alpha, z^{i}\right)_{t}(s)_{j} d i=0 .\end{cases}$

\footnotetext{
${ }^{21}$ This non-convexity remains even if we view purchases and sales of assets as belonging to different spaces.
} 
The first condition requires equilibrium consumption and portfolio plans to be optimal for almost every agent. The second condition requires markets for goods and assets to clear. The third condition requires the equilibrium default rate on an asset to equal the ratio of total loss on that asset to total debt owed on it if total debt owed on it is not zero. If total debt owed is zero the default rate can be any number between zero and one. ${ }^{22}$ The main results in this paper are the following two theorems.

Theorem 1. With the stated assumptions, every economy represented by this model has an equilibrium.

One way to prove this theorem is by setting, for every $s$ and every $t \leq T-1, q_{t}(s)=0$ and $\alpha_{t+1}(s)=1$ and by setting, for every $i, z^{i}=0$. Then asset markets are closed in every period so that, in essence, we have a finite collection of sub-economies (each with one period and $L$ consumption goods) without any asset markets connecting them. The standard proof of existence of an equilibrium (as in an Arrow-Debreu economy) also shows that this economy has an equilibrium. However, such an equilibrium is trivial. Formally, an equilibrium $\left(p, q, \alpha ;\left(x^{i}, z^{i}\right)_{i \in I}\right)$ in an economy is trivial if for every $s$ and every $t \leq T-1$, either $q_{t}(s)=0$ or $\alpha_{t+1}(s)=1$. The proof of existence of an equilibrium that I present in this paper also allows me to prove the following theorem.

Theorem 2. Every economy in which for some $j, s, t, e_{t}(s)<\inf _{i} w_{t}^{i}(s)$ and $A_{t}(s)_{j}>0$ has a non-trivial equilibrium.

Before going through a proof of these theorems let us look at some welfare effects of bankruptcy.

\section{$3 \quad$ Welfare Effects of Bankruptcy}

In this section, using examples of economies represented by my model, we shall see some welfare effects of bankruptcy. As I have mentioned in the introduction of this paper, these welfare effects are well-known in the legal and economics literature. In the general equilibrium framework, many welfare effects of default are already given in Dubey, Geanakoplos, and Shubik (1997). (Some of these are also given in Shubik and Wilson (1977), Zame (1993), Dubey, Geanakoplos, and Zame (1997) and Araujo and Pascoa (1999).) Of course, because Dubey, Geanakoplos, and Shubik (1997) subsume important institutional details into unobservables like utility penalties, they can

\footnotetext{
${ }^{22}$ It is clear that if total debt owed on any asset in any period $t$, state $s$ is zero and the market for that asset clears then the value of $\alpha_{t}(s)_{j}$ is irrelevant.
} 
investigate ideas like default penalties only indirectly and cannot say anything about the effects of exemptions and credit limits on an agent's trading environment. In my model, realistic and observable penalties for default are explicitly built into an agent's trading environment. Thus, it is useful to know that these welfare effects can also be seen in economies represented by my model.

We shall see these welfare effects by considering two examples, each of which has several versions. In this section, to notationally distinguish an equilibrium in my model from an equilibrium in other models, I shall refer to an equilibrium in my model as a Bankruptcy equilibrium.

In the first example, we shall see that an asset market which is useless in the GEI model can become useful when we allow for bankruptcy, that every equilibrium in the Bankruptcy model can be at least as good as the equilibrium in the GEI model and that a Bankruptcy equilibrium can pareto dominate a GEI equilibrium. We shall also see the effects of different levels of exemptions on equilibrium outcomes. If exemptions are too large there is no possibility of debt recovery and hence no trade in the asset.

The intuition for these results is that a creditor is willing to lend money to a debtor if the debtor repays his debt in the state in which the creditor likes to consume even though he is bankrupt in the other state. Also, default rates change the return on an asset; this changes the asset span and can make the asset more useful. Therefore, the institution of bankruptcy allows agents to effectively create a new asset that can lead to a pareto improving equilibrium.

In the second example, we shall see that a pareto optimal Bankruptcy equilibrium strongly pareto dominates the unique equilibrium in the corresponding GEI economy and cannot be pareto dominated by the unique equilibrium in the corresponding Arrow-Debreu economy. Therefore, even when asset markets are incomplete and the GEI equilibrium is strongly pareto inefficient, a Bankruptcy equilibrium can result in an efficient market outcome. We shall also see that an increase in the credit limit of a debtor increases the equilibrium trade in the asset and the equilibrium utility of the creditor even though, in some state of the world, the creditor expects the debtor to be bankrupt and cause him greater losses. Therefore, creditors might want to make it easier for a debtor to take on more debt even when they expect the debtor to become bankrupt in some state of the world. We shall also see that the allocation in a Bankruptcy equilibrium is the same as in the (unique) equilibrium in the corresponding Arrow-Debreu economy. Therefore, even when asset markets are incomplete and the GEI equilibrium is strongly pareto inefficient, a Bankruptcy equilibrium can overcome market incompleteness and achieve the same allocation as in the ArrowDebreu equilibrium. Finally, we shall also see that a decrease in exemption increases the equilibrium 
utility of the creditor and decreases the equilibrium utility of the debtor. Therefore, creditors want to lobby the legislature for lower exemptions and debtors want to oppose such a measure.

The intuition for these results is that if the debtor has enough resources to repay his debt in a state in which the creditor likes to consume then the creditor is better off if the debtor is allowed to take on more debt. This dynamic becomes more beneficial for the creditor when the exemption in this state is low so that the creditor can recover more of his promised payment from the debtor.

In the next subsection, I present the details of the first example. In the subsection after that, I present the details of the second example.

\subsection{First Example}

In this example we shall see that if the decision-making environment of the agents is governed by the GEI model, the only possible equilibrium utilities are those which agents get from consuming their endowments. Therefore, in this environment, markets serve no useful purpose. However, if the decision-making environment is governed by the Bankruptcy model then, in every Bankruptcy equilibrium, utilities are at least as high as those in the GEI model. Also, there are two equilibria in the Bankruptcy model, each of which pareto dominates the equilibrium in the GEI model and in each of which there is trade in the asset and the debtor is not necessarily credit constrained; that is he might choose not to exhaust his credit limit fully. (In fact, these are the only equilibria in which there is trade in the asset.) Therefore, with the additional institution of bankruptcy, markets can become useful and can lead to better outcomes. Finally, we shall see the effect of different levels of exemption on equilibrium outcomes. If exemptions are too large there is no possibility of debt recovery and hence no trade in the asset.

Consider an exchange economy in which there are two time periods, indexed 1 and 2 and two states of the world, indexed 1 and 2. There is no information in period 1 and full information in period 2. There is one consumption good in period 1 and in each state in period 2. The consumption space is $R_{+}^{3}$. An element $x=\left(x_{1}, x_{2}(1), x_{2}(2)\right)$ in the consumption space is a consumption plan which entails consumption of $x_{1}$ units of the consumption good in period 1 and $x_{2}(s)$ units of the consumption good in state $s(s=1,2)$ in period 2. There is one asset, given by $A=\left[\begin{array}{l}1 \\ 1\end{array}\right]$. The portfolio space is $R$. An element $z$ of the portfolio space is a portfolio plan which entails holding of $z$ units of the asset. Prices in period 1 are given by $\left(p_{1}, q\right)$ where $p_{1}$ is the price of the consumption good and $q$ the price of the asset. The price of the consumption good is 1 in each state in period 
2. There are two agents, indexed 1 and 2. The preference and endowment of each agent is

$$
\begin{array}{ll}
U^{1}=x_{1}+x_{2}(1)+100 x_{2}(2), & w^{1}=(1,10,1), \\
U^{2}=x_{1}+100 x_{2}(1)+x_{2}(2), & w^{2}=(1,1,10) .
\end{array}
$$

In the GEI model, ${ }^{23}$ if prices are $\left(p_{1}, q\right)$ with $p_{1}>0$, the affordability constraints for agents $i=1,2$ that are relevant to this analysis are

$$
0 \leq x_{1}^{i}=1-\frac{q}{p_{1}} z^{i} \quad \text { and } \quad 0 \leq x_{2}^{i}(s)=w_{2}^{i}(s)+z^{i} \quad(s=1,2)
$$

These constraints mean that in every period and state, the value of consumption of every agent equals his income. In the Bankruptcy model, suppose the exemption is $(e(1), e(2))$ and the credit limit for agent $i$ is $C^{i}(q)$. If prices are $\left(p_{1}, q\right)$ with $p_{1}>0$ and default rates are $\alpha=(\alpha(1), \alpha(2))$, the affordability constraints for agents $i=1,2$ that are relevant to this analysis are

$0 \leq x_{1}^{i}=1-\frac{q}{p_{1}} z^{i}$ and $0 \leq x_{2}^{i}(s)=\max \left(w_{2}^{i}(s)+(1-\alpha(s)) z_{+}^{i}-z_{-}^{i}, \min \left(e(s), w_{2}^{i}(s)\right)\right)(s=1,2)$.

Also, credit limit restrictions mean that for every agent $i, z_{-}^{i} \leq C^{i}(q)$.

In this example, if agents just consume their endowments, their utilities are $\left(U^{1}, U^{2}\right)=(111,111)$ and if their decision-making environment is determined by the GEI model then markets serve no useful purpose because the unique GEI equilibrium utilities are also $\left(U^{1}, U^{2}\right)=(111,111)$. We can check for the GEI equilibrium as follows. Using the affordability constraints for each agent, we can re-write the utility of each agent as $U^{1}=1-\frac{q}{p_{1}} z^{1}+10+z^{1}+100\left(1+z^{1}\right)=111+\left(101-\frac{q}{p_{1}}\right) z^{1}$ so that $\frac{d U^{1}}{d z^{1}} \geq 0 \Leftrightarrow p_{1} \geq \frac{1}{102}$ and $U^{2}=111+\left(101-\frac{q}{p_{1}}\right) z^{2}$ so that $\frac{d U^{2}}{d z^{2}} \geq 0 \Leftrightarrow p_{1} \geq \frac{1}{102}$. This helps us determine the optimal portfolio choice of each agent. If $p_{1}<\frac{1}{102}$, the optimal portfolio choice of each agent is $z^{1}=z^{2}=-1$. If $p_{1}>\frac{1}{102}$, the optimal portfolio choice of each agent is $z^{1}=z^{2}=\frac{p_{1}}{q}$. If $p_{1}=\frac{1}{102}$, the optimal portfolio choice of each agent is $z^{1}, z^{2} \in\left[-1, \frac{1}{101}\right]$. Notice that if the asset market is to clear it must be that $p_{1}=\frac{1}{102}$. Therefore, the unique equilibrium prices in the GEI model are $\left(p_{1}, q\right)=\left(\frac{1}{102}, \frac{101}{102}\right)$. For $\xi \in\left[-\frac{1}{101}, \frac{1}{101}\right]$, the corresponding consumption and portfolio plan for agent 1 is given by $x^{1}=(1-101 \xi, 10+\xi, 1+\xi), z^{1}=\xi$ and that for agent 2 is given by $x^{2}=(1+101 \xi, 1-\xi, 10-\xi), z^{2}=-\xi$. The unique equilibrium utilities are given by $\left(U^{1}, U^{2}\right)=(111,111)$ and in this situation, markets serve no useful purpose.

Notice that in this example, every Bankruptcy equilibrium is at least as good as the GEI equilibrium. This is because for each agent, the consumption and portfolio plan consisting of his

\footnotetext{
${ }^{23}$ For details of the GEI model, see the book by Magill and Quinzii (1996).
} 
endowment and no trade in the asset is always in the agent's budget set. (This is independent of exemptions and credit limits.) Therefore, in each bankruptcy equilibrium, $U^{1} \geq 111$ and $U^{2} \geq 111$.

Also, the following Bankruptcy equilibrium pareto dominates the GEI equilibrium and in this equilibrium there is trade in the asset and the debtor is not credit constrained. Suppose $(e(1), e(2))=(1,1)$ and $C^{1}(q)=C^{2}(q)=8 q$. Then

$$
\left(p_{1}, q\right)=\left(\frac{1}{2}, \frac{1}{2}\right), \quad \alpha=(0,1), \quad x^{1}=(2,9,1), z^{1}=-1, \quad x^{2}=(0,2,10), z^{2}=1
$$

is an equilibrium with utilities $\left(U^{1}, U^{2}\right)=(111,210)$. To check that this is an equilibrium, notice that all markets are clearing, the default rate calculations are correct and for each agent, his plan is in his budget set. The only thing left to confirm is that agents are optimizing. Let us first look at the plan for agent 1 . Substituting the value of $q$ in the credit limit for agent 1 shows that every admissible portfolio, $z^{1}$, must satisfy $z_{-}^{1} \leq 4$. The affordability constraints which are relevant to this analysis are

$$
0 \leq x_{1}^{1}=1-z^{1}, \quad 0 \leq x_{2}^{1}(1)=10+z^{1} \quad\left(\text { since } z_{-}^{1} \leq 4\right) \quad \text { and } \quad 0 \leq x_{2}^{1}(2)=1
$$

whence, $U^{1}=1-z^{1}+z^{1}+10+100(1)=111$ (irrespective of choice of $z^{1}$ ). Therefore, the given plan is optimal in the budget set for agent 1 . Similarly, the analysis for agent 2 gives us ${ }^{24}$ $U^{2}=1-z^{2}+100\left(\max \left(1+z^{2}, 1\right)\right)+10-z_{-}^{2}$. If $z^{2} \leq 0$, then $U^{2}=1-z^{2}+100+10+z^{2}=111$ (irrespective of $z^{2}$ ). If $z^{2} \geq 0$, then $U^{2}=1-z^{2}+100\left(1+z^{2}\right)+10=111+99 z^{2}$ whence the optimal choice of $z^{2}$ is 1 and $U^{2}=210$. We conclude that the given plan is optimal in the budget set for agent 2 .

With the same exemption and credit limits and using the same argument as above, it is easy to check that

$$
\left(p_{1}, q\right)=\left(\frac{1}{2}, \frac{1}{2}\right), \quad \alpha=(1,0), \quad x^{1}=(0,10,2), z^{1}=1, \quad x^{2}=(2,1,9), z^{2}=-1
$$

is also a Bankruptcy equilibrium that pareto dominates the GEI equilibrium and in this equilibrium also there is trade in the asset and the debtor is not credit constrained.

With the same exemption and credit limits, these are the only Bankruptcy equilibria in which there is trade in the asset. We can see this as follows. Suppose there is an equilibrium with $p_{1}<\frac{1}{2}$ and $z^{1} \neq 0$. One possibility is that agent 1 sells the asset. If $z^{1}<0$ then, because $-8 \leq z^{1}$, we have

\footnotetext{
${ }^{24}$ for portfolio admissibility, $z_{-}^{2} \leq 4$. The affordability constraints are $0 \leq x_{1}^{2}=1-z^{2} \quad\left(\Rightarrow z^{2} \leq 1\right), 0 \leq x_{2}^{2}(1)=$ $\max \left(1+z^{2}, 1\right)$, and $0 \leq x_{2}^{2}(2)=10-z_{-}^{2} \quad\left(\right.$ since $\left.z_{-}^{2} \leq 4\right)$.
} 
$U^{1}=1-\frac{q}{p_{1}} z^{1}+\max \left(10+z^{1}, 1\right)+100=111+\left(1-\frac{q}{p_{1}}\right) z^{1}$ so that $\frac{d U^{1}}{d z^{1}} \geq 0 \Leftrightarrow p_{1} \geq \frac{1}{2}$. Therefore, the optimal portfolio choice for agent 1 is $z^{1}=-8 q$. Also, $-8 \leq z^{1}<0$ implies that the loss from agent one in state one is zero and in state two is $z_{-}^{1}$ so that the default rate is $\alpha=(0,1)$. Also, asset market clearing implies that $z^{2}>0$ so that $U^{2}=1-\frac{q}{p_{1}} z^{2}+100\left(1+z^{2}\right)+10$ and hence $\frac{d U^{2}}{d z^{2}} \geq 0 \Leftrightarrow p_{1} \geq \frac{1}{101}$. If $p_{1}<\frac{1}{101}$ then no positive portfolio choice is optimal for agent 2 which contradicts $z^{2}>0$. If $p_{1}=\frac{1}{101}$ then agent 1 sells $8 q=\frac{800}{101}$ units of the asset but agent 2 can buy at most $\frac{1}{100}$ units of the asset. This contradicts asset market clearing. If $\frac{1}{101}<p_{1}<\frac{1}{2}$ then the optimal portfolio choice for agent 2 is $z^{2}=\frac{p_{1}}{q}=\frac{1-q}{q}$. Asset market clearing implies that the price of the asset must satisfy $-8 q=\frac{1-q}{q}$. The only positive root of this quadratic is $q=\frac{-1+\sqrt{33}}{16} \approx 0.297$ so that $p_{1}>\frac{1}{2}$, a contradiction. Therefore, it cannot be that $z^{1}<0$. The other possibility is that agent 1 buys the asset. If $z^{1}>0$ then asset market clearing implies that $z^{2}<0$. Using the same argument as above we can see that this is impossible. Therefore, there is no equilibrium with $p_{1}<\frac{1}{2}$ and $z^{1} \neq 0$. Suppose there is an equilibrium with $p_{1}>\frac{1}{2}$ and $z^{1} \neq 0$. If $z^{1}<0$ then $U^{1}=111+\left(1-\frac{q}{p_{1}}\right) z^{1}$ so that $\frac{d U^{1}}{d z^{1}} \geq 0 \Leftrightarrow p_{1} \geq \frac{1}{2}$ from which it follows that no negative portfolio choice is optimal for agent 1 which contradicts $z^{1}<0$. Similarly, if $z^{1}>0$ then $z^{2}<0$ so that $\frac{d U^{2}}{d z^{2}} \geq 0 \Leftrightarrow p_{1} \geq \frac{1}{2}$ from which it follows that no negative portfolio choice is optimal for agent 2 which contradicts $z^{2}<0$. Therefore, there is no equilibrium with $p_{1}>\frac{1}{2}$ and $z^{1} \neq 0$. We conclude that in an equilibrium in which there is trade in the asset the prices have to be $\left(p_{1}, q\right)=\left(\frac{1}{2}, \frac{1}{2}\right)$. With a little more work, it is easy to see that with the given exemptions and credit limits, the only equilibria in which there is trade in the asset are the ones given above.

Now let us see how exemption levels can affect equilibrium outcomes. Intuitively, when exemptions are large, a creditor wants to buy less of the asset and the debtor wants to sell more of the asset because large exemptions reduce the portion of a debtor's income which can be confiscated to repay his debt. If the exemption for an agent is too large it could be that in an equilibrium this agent cannot sell the asset.

The next version of this example shows that if exemptions are too large and prices are $\left(p_{1}, q\right)=$ $\left(\frac{1}{2}, \frac{1}{2}\right)$ then in every Bankruptcy equilibrium there is no trade. Suppose $(e(1), e(2))=(e(1), 1)$ with $6<e(1)<10,6<e(2)<10 C^{1}(q)=C^{2}(q)=8 q$ and $\left(p_{1}, q\right)=\left(\frac{1}{2}, \frac{1}{2}\right)$. Suppose that at these prices there is an equilibrium with $z^{1}<0$. If $e(1)-10 \leq z^{1}<0$ then $U^{1}=1-z^{1}+z^{1}+10+100(1)=111$ (irrespective of choice of $z^{1}$ ) and if $-4 \leq z^{1} \leq e(1)-10$ then $U^{1}=101+e(1)-z^{1}$ so that the optimal portfolio choice for agent 1 is $z^{1}=-4$ and $U^{1}=105+e(1)>111$. Asset market clearing implies that $z^{2}=4$. Combined with the affordability constraint for agent 2 in period 1 we have 
$0 \leq 1-z^{2}=-3$, a contradiction. Therefore, with these prices, in any equilibrium in which there is trade in the asset, it must be that $z^{1}>0$ and hence $z^{2}<0$. But a similar calculation shows that $z^{2}>0$, a contradiction. Thus in this version there is no trade in equilibrium. This result generalizes a little, as the following proposition shows.

Proposition. Consider the Bankruptcy model with 2 time periods and 1 asset. In every economy represented by this model, if for every $s A(s)>0 \Rightarrow e(s) \geq \sup _{i} w_{2}^{i}(s)$ then in every Bankruptcy equilibrium of this economy there is no trade in the asset.

Proof. Let $\left(p, q, \alpha,\left(x^{i}, z^{i}\right)_{i \in I}\right)$ be an equilibrium. If $q=0$ then the credit limit for almost every agent is 0 so that almost nobody sells the asset. As the asset market is clearing it must also be that almost nobody is buying the asset. Also, if $q>0$ there is no trade in the asset. For if there is trade in the asset, that is, if $\mu\left(\left\{i \in I \mid z_{-}^{i}>0\right\}\right)>0$ then for every state $s$ such that $A(s)>0, \mu\left(\left\{i \in I \mid p_{2}(s)_{1} A(s) z_{-}^{i}>0\right\}\right)>0$. The aggregate loss in such a state is $\int_{I} \gamma^{i}(s) d i=$

$\int_{I} p_{2}(s){ }_{1} A(s) z_{-}^{i} d i>0$ so that $\alpha(s)=\frac{\int_{I} \beta^{i}(s) d i}{\int_{I} \gamma^{i}(s) d i}$. Also, the loss from agent $i$ in such a state is $\lambda^{i}(s)=$ $\min \left(p_{2}(s)_{1} A(s) z_{-}^{i}-p_{2}(s)_{1}(1-\alpha(s)) A(s) z_{+}^{i}, 0\right)$ from which it follows that the loss from agent $i$ on this asset is $\beta^{i}(s)=p_{2}(s)_{1} A(s) z_{-}^{i}$. Therefore, $\alpha(s)=1$ so that for every $i, p_{2}(s)_{1}(1-\alpha(s)) A(s) z_{+}^{i}=0$. Of course, in a state in which $A(s)=0$, we also have, for every $i, p_{2}(s)_{1}(1-\alpha(s)) A(s) z_{+}^{i}=0$. Thus, in every state and for every $i, p_{2}(s)_{1}(1-\alpha(s)) A(s) z_{+}^{i}=0$. As $q>0$, using strong monotonicity of preferences, it must be that for almost every $i, z_{+}^{i}=0$ and this contradicts the fact that asset markets are clearing. Therefore, whether $q=0$ or $q>0$ there is no trade in the asset.

An application of this result to this example shows that if exemptions are too large $(e(1) \geq 10$ and $e(2) \geq 10)$ then in every Bankruptcy equilibrium there is no trade in the asset and hence the unique equilibrium utilities are $\left(U^{1}, U^{2}\right)=(111,111)$. Notice that this result is independent of credit limits and the proof uses only strong monotonicity of preferences. An analogous result holds in the model with many time periods and one asset. We shall not look at it in this paper. A summary of the different versions of this example is given in Table 1 at the end of this paper.

\subsection{Second Example}

In this example we shall see that if the decision-making environment of the agents is governed by the Arrow-Debreu model then there is a unique equilibrium which is, of course, pareto efficient. If this environment is governed by the GEI model then there is a unique equilibrium which is strongly pareto inefficient. If this environment is governed by the Bankruptcy model then there is 
an equilibrium which is pareto optimal, which strongly dominates the GEI equilibrium and which cannot be dominated by the Arrow-Debreu equilibrium. Therefore, even when asset markets are incomplete and the GEI equilibrium is strongly pareto inefficient, a Bankruptcy equilibrium can result in an efficient market outcome. We shall also see that an increase in the credit limit of a debtor increases the equilibrium trade in the asset and the equilibrium utility of the creditor even though, in some state of the world, the creditor expects the debtor to be bankrupt and cause him greater losses. Therefore, creditors might want to make it easier for a debtor to take on more debt even when they expect the debtor to become bankrupt in some state of the world. We shall also see that the allocation in a Bankruptcy equilibrium is the same as in the (unique) equilibrium in the corresponding Arrow-Debreu economy. Therefore, even when asset markets are incomplete and the GEI equilibrium is strongly pareto inefficient, a Bankruptcy equilibrium can overcome market incompleteness and achieve the same allocation as in the Arrow-Debreu equilibrium. Finally, we shall also see that a decrease in exemption increases the equilibrium utility of the creditor and decreases the equilibrium utility of the debtor. Therefore, creditors want to lobby the legislature for lower exemptions and debtors want to oppose such a measure.

Consider an exchange economy in which there are two time periods, indexed 1 and 2 and two states of the world, indexed 1 and 2. There is no information in period 1 and full information in period 2. There is one consumption good in period 1 and in each state in period 2. The consumption space is $R_{+}^{3}$. An element $x=\left(x_{1}, x_{2}(1), x_{2}(2)\right)$ in the consumption space is a consumption plan which entails consumption of $x_{1}$ units of the consumption good in period 1 and $x_{2}(s)$ units of the consumption good in state $s(s=1,2)$ in period 2. There is one asset, given by $A=\left[\begin{array}{l}1 \\ 1\end{array}\right]$. The portfolio space is $R$. An element $z$ of the portfolio space is a portfolio plan which entails holding of $z$ units of the asset. Prices in period 1 are given by $\left(p_{1}, q\right)$ where $p_{1}$ is the price of the consumption good and $q$ the price of the asset. These prices satisfy $0 \leq p_{1} \leq 1$ and $q=1-p_{1}$. The price of the consumption good is 1 in each state in period 2. There are two agents, indexed 1 and 2 . The preference and endowment of each agent is

$$
\begin{array}{ll}
U^{1}=100 x_{1}+x_{2}(1)+50 x_{2}(2), & w^{1}=(1,10,1), \\
U^{2}=x_{1}+100 x_{2}(1)+x_{2}(2), & w^{2}=(10,1,0) .
\end{array}
$$

In the GEI model, if prices are $\left(p_{1}, q\right)$ with $p_{1}>0$, the affordability constraints for agents $i=1,2$ that are relevant to this analysis are

$$
0 \leq x_{1}^{i}=1-\frac{q}{p_{1}} z^{i} \quad \text { and } \quad 0 \leq x_{2}^{i}(s)=w_{2}^{i}(s)+z^{i} \quad(s=1,2) .
$$


These constraints mean that in every period and state, the value of consumption of every agent equals his income. In the Bankruptcy model, suppose the exemption is $(e(1), e(2))$ and the credit limit for agent $i$ is $C^{i}(q)$. If prices are $\left(p_{1}, q\right)$ with $p_{1}>0$ and default rates are $\alpha=(\alpha(1), \alpha(2))$, the affordability constraints for agents $i=1,2$ that are relevant to this analysis are

$0 \leq x_{1}^{i}=1-\frac{q}{p_{1}} z^{i}$ and $0 \leq x_{2}^{i}(s)=\max \left(w_{2}^{i}(s)+(1-\alpha(s)) z_{+}^{i}-z_{-}^{i}, \min \left(e(s), w_{2}^{i}(s)\right)\right)(s=1,2)$.

Also, credit limit restrictions mean that for every agent $i, z_{-}^{i} \leq C^{i}(q)$.

If the agents just consume their endowments their utilities are $\left(U^{1}, U^{2}\right)=(160,110)$, if their decision-making environment is determined by the complete markets Arrow-Debreu model their unique (and pareto efficient) equilibrium utilities are $\left(U^{1}, U^{2}\right)=(1150,1100)^{25}$ and if their decisionmaking environment is determined by the GEI model their unique (and strongly pareto inefficient) equilibrium utilities are $\left(U^{1}, U^{2}\right)=(1109,201)$. We can check for the GEI equilibrium as follows. Using the affordability constraints for each agent, we can re-write the utility of each agent as $U^{1}=100\left(1-\frac{q}{p_{1}} z^{1}\right)+10+z^{1}+50\left(1+z^{1}\right)=160+\left(51-\frac{100 q}{p_{1}}\right) z^{1}$ so that $\frac{d U^{1}}{d z^{1}} \geq 0 \Leftrightarrow p_{1} \geq \frac{100}{151}$ and $U^{2}=110+\left(101-\frac{q}{p_{1}}\right) z^{2}$ so that $\frac{d U^{2}}{d z^{2}} \geq 0 \Leftrightarrow p_{1} \geq \frac{1}{102}$. This helps us determine the optimal portfolio choice of each agent. If $p_{1}<\frac{1}{102}$, the optimal portfolio choice of each agent is $z^{1}=-1$ and $z^{2}=0$. If $p_{1}=\frac{1}{102}$, the choice is $z^{1}=-1$ and $z^{2} \in\left[0, \frac{10}{101}\right]$. If $\frac{1}{10}<p_{1}<\frac{100}{151}$, the choice is $z^{1}=-1$ and $z^{2}=\frac{10 p_{1}}{q}$. If $p_{1}=\frac{100}{151}$, the choice is $z^{1} \in\left[-1, \frac{100}{151}\right]$ and $z^{2}=\frac{1000}{51}$. If $\frac{100}{151}<p_{1}$, the choice is $z^{1}=\frac{p_{1}}{q}$ and $z^{2}=\frac{10 p_{1}}{q}$. Thus, if asset market is to clear it must be that $\frac{10 p_{1}}{q}=1$ and hence $p_{1}=\frac{1}{11}$. Therefore,

$$
\left(p_{1}, q\right)=\left(\frac{1}{11}, \frac{10}{11}\right), \quad x^{1}=(11,9,0), z^{1}=-1, \quad x^{2}=(0,2,1), z^{2}=1
$$

is the unique equilibrium with utilities $\left(U^{1}, U^{2}\right)=(1109,201)$.

The following Bankruptcy equilibrium is pareto efficient, strongly pareto dominates the GEI equilibrium and cannot be pareto dominated by the Arrow-Debreu equilibrium. Therefore, even when asset markets are incomplete and the GEI equilibrium is strongly pareto inefficient, a Bankruptcy equilibrium can result in an efficient market outcome. Suppose $(e(1), e(2))=(1,1), C^{1}(q)=\frac{19 \times 9}{10} q$ and $C^{2}(q)=\frac{19}{10} q$. Then

$$
\left(p_{1}, q\right)=\left(\frac{9}{19}, \frac{10}{19}\right), \quad \alpha=(0,1), \quad x^{1}=(11,1,1), z^{1}=-9, \quad x^{2}=(0,10,0), z^{2}=9
$$

is an equilibrium with utilities $\left(U^{1}, U^{2}\right)=(1151,1000)$. To see that this is a Bankruptcy equilibrium, substitute $\xi=9$ in the parameterization given below.

\footnotetext{
${ }^{25}$ the unique equilibrium prices and allocations are $\left(p_{1}, p_{2}(1), p_{2}(2)\right)=\left(\frac{2}{5}, \frac{2}{5}, \frac{1}{5}\right)$ and $x^{1}=(11,0,1), \quad x^{2}=(0,11,0)$.
} 
In a parameterized version of this example, we can see that an increase in the credit limit of a debtor increases the equilibrium trade in the asset and the equilibrium utility of the creditor even though, in some state of the world, the creditor expects the debtor to be bankrupt and cause him greater losses. Therefore, creditors might want to make it easier for a debtor to take on more debt even when they expect the debtor to be bankrupt in some state of the world. Suppose $(e(1), e(2))=(1,1)$. Fix $\xi \in[1,9]$ and let $C^{1}(q)=\frac{(10+\xi) \xi}{10} q$ and $C^{2}(q)=\frac{10+\xi}{10} q$. Then $\left(p_{1}, q\right)=\left(\frac{\xi}{10+\xi}, \frac{10}{10+\xi}\right), \quad \alpha=(0,1), \quad x^{1}=(11,10-\xi, 1), z^{1}=-\xi, \quad x^{2}=(0,1+\xi, 0), z^{2}=\xi$ is an equilibrium with utilities $\left(U^{1}, U^{2}\right)=(1160-\xi, 100+100 \xi)$. Notice that this equilibrium allocation is pareto efficient. To check that this is an equilibrium, notice that all markets are clearing, the default rate calculations are correct and for each agent, his plan is in his budget set. The only thing left to confirm is that agents are optimizing. Let us first look at the plan for agent 1. Substituting the value of $q$ in the credit limit for agent 1 gives us, for portfolio admissibility, $z_{-}^{1} \leq \xi$. If $z^{1} \geq 0$ then $U^{1}=100\left(1-\frac{q}{p_{1}} z^{1}\right)+10+(1-\alpha(1)) z^{1}+50\left(1+(1-\alpha(2)) z^{1}\right)=160+\left(1-\frac{1000}{\xi}\right) z^{1}$. Since the coefficient for $z^{1}$ is negative the optimal portfolio choice is zero and the corresponding utility is $U^{1}=160$. If $-\xi \leq z^{1} \leq 0$ then $U^{1}=100\left(1-\frac{q}{p_{1}} z^{1}\right)+10+z^{1}+50=160+\left(1-\frac{1000}{\xi}\right) z^{1}$ so that the optimal portfolio choice is $z^{1}=-\xi$ and the corresponding utility is $U^{1}=1160-\xi$. Therefore, the given plan is optimal in the budget set for agent 1 . For agent 2, substituting the value of $q$ in the credit limit for agent 1 gives us, for portfolio admissibility, $z_{-}^{2} \leq 1$. If $z^{2} \geq 0$ then $U^{2}=\left(10-\frac{q}{p_{1}} z^{2}\right)+100\left(1+(1-\alpha(1)) z^{2}\right)+(1-\alpha(2)) z^{2}=110+\left(100-\frac{10}{\xi}\right) z^{2}$. Since the coefficient for $z^{2}$ is positive the optimal portfolio choice is $z^{2}=10 \frac{\xi}{10}$ and the corresponding utility is $U^{2}=100+100 \xi$. If $-1 \leq z^{2} \leq 0$ then $U^{2}=110+\left(100-\frac{10}{\xi}\right) z^{2}$ so that the optimal portfolio choice is 0 and the corresponding utility is $U^{2}=110$. Therefore, the given plan is optimal in the budget set for agent 2 .

Notice that in this parameterizaton, when $\xi=9$, the equilibrium allocation is very close to the equilibrium allocation for the Arrow-Debreu model. It is the exemption in state 1 which prevents the creditor from recovering the last unit of consumption from the debtor. This creates an incentive for the creditor to lobby for lower exemptions. One might guess that if the exemption in state 1 were lower the creditor is willing to extend even more credit to the debtor. This is correct, as we can see below.

In the following Bankruptcy equilibrium the allocation is the same as the one in the unique equilibrium in the corresponding Arrow-Debreu economy. Therefore, even when asset markets 
are incomplete and the GEI equilibrium is strongly pareto inefficient, a Bankruptcy equilibrium can overcome market incompleteness and achieve the same allocation as in the Arrow-Debreu equilibrium. Suppose $(e(1), e(2))=(0,1), C^{1}(q)=20 q$ and $C^{2}(q)=2 q$. Then

$$
\left(p_{1}, q\right)=\left(\frac{1}{2}, \frac{1}{2}\right) ; \quad \alpha=(0,1) ; \quad x^{1}=(11,0,1), z^{1}=-10 ; \quad x^{2}=(0,11,0), z^{2}=10
$$

is an equilibrium with utilities $\left(U^{1}, U^{2}\right)=(1150,1100)$. To see that this is a Bankruptcy equilibrium, substitute $\xi=0$ in the parameterization given below.

In another parameterized version of this example, we can see that a decrease in the exemption in state 1 can further increase the equilibrium trade in the asset and the equilibrium utility of the creditor and decrease the equilibrium utility of the debtor. Therefore, creditors want to lobby a legislature for lower exemptions and debtors want to oppose such a measure. Fix $\xi \in[0,1]$. Suppose $(e(1), e(2))=(\xi, 1), C^{1}(q)=\frac{(20-\xi)(10-\xi)}{10} q$ and $C^{2}(q)=\frac{(20-\xi)(1-\xi)}{10} q$. Then $\left(p_{1}, q\right)=\left(\frac{10-\xi}{20-\xi}, \frac{10}{20-\xi}\right), \quad \alpha=(0,1), \quad x^{1}=(11, \xi, 1), z^{1}=\xi-10, \quad x^{2}=(0,11-\xi, 0), z^{2}=10-\xi$ is an equilibrium with utilities $\left(U^{1}, U^{2}\right)=(1150+\xi, 1100-100 \xi)$. Notice that this equilibrium allocation is pareto efficient. To check that this is an equilibrium, notice that all markets are clearing, the default rate calculations are correct and for each agent, his plan is in his budget set. The only thing left to confirm is that agents are optimizing. Let us first look at the plan for agent 1. Substituting the value of $q$ in the credit limit for agent 1 gives us, for portfolio admissibility, $z_{-}^{1} \leq$ $10-\xi$. If $z^{1} \geq 0$ then $U^{1}=100\left(1-\frac{q}{p_{1}} z^{1}\right)+10+(1-\alpha(1)) z^{1}+50\left(1+(1-\alpha(2)) z^{1}\right)=160+\left(1-\frac{1000}{10-\xi}\right) z^{1}$. Since the coefficient for $z^{1}$ is negative the optimal portfolio choice is zero and the corresponding utility is $U^{1}=160$. If $\xi-10 \leq z^{1} \leq 0$ then $U^{1}=100\left(1-\frac{q}{p_{1}} z^{1}\right)+10+z^{1}+50=160+\left(1-\frac{1000}{10-\xi}\right) z^{1}$ so that the optimal portfolio choice is $z^{1}=\xi-10$ and the corresponding utility is $U^{1}=1150+\xi$. Therefore, the given plan is optimal in the budget set for agent 1. For agent 2, substituting the value of $q$ in the credit limit for agent 1 gives us, for portfolio admissibility, $z_{-}^{2} \leq 1-\xi$. If $z^{2} \geq 0$ then $U^{2}=\left(10-\frac{q}{p_{1}} z^{2}\right)+100\left(1+(1-\alpha(1)) z^{2}\right)+(1-\alpha(2)) z^{2}=110+\left(100-\frac{10}{10-\xi}\right) z^{2}$. Since the coefficient for $z^{2}$ is positive the optimal portfolio choice is $z^{2}=10 \frac{10-\xi}{10}$ and the corresponding utility is $U^{2}=1100-\xi$. If $\xi-1 \leq z^{2} \leq 0$ then $U^{2}=110+\left(100-\frac{10}{10-\xi}\right) z^{2}$ so that the optimal portfolio choice is 0 and the corresponding utility is $U^{2}=110$. Therefore, the given plan is optimal in the budget set for agent 2 .

A summary of the different versions of this example is given in Table 2 at the end of the paper. 


\section{Existence of Equilibrium}

To prove the two theorems mentioned above, I proceed in the following manner. First, I truncate the price space so that prices are bounded away from zero. Then, I summarize the relevant information in the economy in a correspondence on a space which depends on the truncated price space. By Kakutani's theorem, this correspondence has a fixed point. As the truncated price space approaches the untruncated space, there is a sequence of fixed points. From this sequence we get a convergent subsequence, the limit of which gives us an equilibrium.

Let us truncate the price space as follows. For $n \geq L+J$ and $n \neq \infty$, the $n$-truncated price space in period $t \leq T-1$ is $\hat{\Delta}_{n, t}=\left\{\left(p_{t}, q_{t}\right) \in \Delta_{t} \mid\left(p_{t}, q_{t}\right) \geq \frac{1}{n} 1\right\}$ (here, 1 is the vector of ones in $\left.\mathcal{R}_{t}^{L+J}\right)$ and in period $t=T$ is $\hat{\Delta}_{n, T}=\left\{\left(p_{T}, 0\right) \in \Delta_{T} \mid p_{T} \geq \frac{1}{n} 1\right\}$ (here, 1 is the vector of ones in $\left.\mathcal{R}_{T}^{L}\right)$. The $n$-truncated price space is $\hat{\Delta}_{n}=\underset{t=1}{\times} \hat{\Delta}_{n, t}$.

The correspondence that I use to summarize the relevant information in the economy is a product of three correspondences. The first correspondence is the aggregate extended demand correspondence - it relates market variables (price and default rate) to aggregate individual choices (aggregate demand and the corresponding total loss and total debt). The second correspondence is the price correspondence - it relates possible levels of excess demand to prices. The third correspondence is the default rate correspondence - it relates possible levels of total loss and total debt to default rates associated with them.

First, let us look at the aggregate extended demand correspondence and some of its properties. As a preliminary step, let us look at the demand correspondence. The demand correspondence for agent $i$ associates to every $(p, q, \alpha)$ in $\Delta \times \nabla$ the set $D^{i}(p, q, \alpha)$. Let $P_{0}=$ $\left\{(p, q) \in \Delta \mid\right.$ for some $\left.s, t, p_{t}(s)=0\right\}$. Then we have the following lemma.

Lemma 2. For every $i$, the demand correspondence for agent $i$ has closed graph on $\left(\Delta \backslash P_{0}\right) \times \nabla$.

Proof. Suppose $\left(p_{m}, q_{m}, \alpha_{m}, x_{m}^{i}, z_{m}^{i}\right) \rightarrow\left(p, q, \alpha, x^{i}, z^{i}\right),\left(p_{m}, q_{m}\right)$ and $(p, q)$ not in $P_{0}$ and $\left(x_{m}^{i}, z_{m}^{i}\right) \in$ $D^{i}\left(p_{m}, q_{m}, \alpha_{m}\right)$. We need to verify that $\left(x^{i}, z^{i}\right) \in D^{i}(p, q, \alpha)$. It is easy to see that $\left(x^{i}, z^{i}\right) \in$ $B^{i}(p, q, \alpha)$. So suppose $\left(\dot{x}^{i}, \dot{z}^{i}\right) \in B^{i}(p, q, \alpha)$. We want to conclude that $x^{i} \succeq^{i} \dot{x}^{i}$.

Fix $\xi \in(0,1)$ arbitrarily. Let us first confirm that for all $m$ sufficiently large, $\left(\xi \dot{x}^{i}, \xi \dot{z}^{i}\right) \in$ $B^{i}\left(p_{m}, q_{m}, \alpha_{m}\right)$. Since for every $s, t, \xi f^{i}\left(p, q, \alpha, \dot{z}^{i}\right)_{t}(s)<f^{i}\left(p, q, \alpha, \xi \dot{z}^{i}\right)_{t}(s)$ and $\xi \epsilon^{i}\left(p, q, \alpha, \dot{z}^{i}\right)_{t}(s)<$ $\epsilon^{i}\left(p, q, \alpha, \xi \dot{z}^{i}\right)_{t}(s),\left(\xi \dot{x}^{i}, \xi \dot{z}^{i}\right)$ is strictly affordable at $(p, q, \alpha)$. Thus, there is $m_{0}$ such that $m \geq m_{0}$ implies that $\left(\xi \dot{x}^{i}, \xi \dot{z}^{i}\right)$ is $\left(p_{m}, q_{m}, \alpha_{m}\right)$-affordable. To check for admissibility, temporarily fix $j, s, t$ with $t \leq T-1$. Suppose there is $s^{\prime} \in E_{t}(s)$ such that $A_{t+1}\left(s^{\prime}\right)_{j}>0$. If either $\left(\dot{z}_{t}^{i}(s)_{-}\right)_{j}=0$ or $A_{t+1}(s)_{j}=$ 
0 then $A_{t+1}(s)_{j}\left(\left(\xi \dot{z}^{i}\right)_{t}(s)_{-}\right)_{j}=0$ otherwise $A_{t+1}(s)_{j}\left(\left(\xi \dot{z}^{i}\right)_{t}(s)_{-}\right)_{j}<C^{i}\left(q, \beta^{i}\left(p, q, \alpha, \xi z^{i}\right)\right)_{t}(s)_{j}$. In either case, there is $m_{t}(s)_{j} \geq m_{0}$ such that $m \geq m_{t}(s)_{j}$ implies

$$
A_{t+1}(s)_{j}\left(\left(\xi \dot{z}^{i}\right)_{t}(s)_{-}\right)_{j} \leq C^{i}\left(q_{m}, \beta^{i}\left(p_{m}, q_{m}, \alpha_{m}, \xi \dot{z}^{i}\right)\right)_{t}(s)_{j}
$$

Now, suppose that for every $s^{\prime} \in E_{t}(s) A_{t+1}\left(s^{\prime}\right)_{j}=0$. If $\left(\dot{z}_{t}^{i}(s)_{-}\right)_{j}=0$ then $\left(\left(\xi z^{i}\right)_{t}(s)_{-}\right)_{j}=0$ otherwise $\left(\left(\xi z^{i}\right)_{t}(s)_{-}\right)_{j}<C^{i}\left(q, \beta^{i}\left(p, q, \alpha, \xi z^{i}\right)\right)_{t}(s)_{j}$. In either case we may choose $m_{t}(s)_{j} \geq m_{0}$ such that $m \geq m_{t}(s)_{j}$ also implies that

$$
\left(\left(\xi \dot{z}^{i}\right)_{t}(s)_{-}\right)_{j} \leq C^{i}\left(q_{m}, \beta^{i}\left(p_{m}, q_{m}, \alpha_{m}, \xi \dot{z}^{i}\right)\right)_{t}(s)_{j}
$$

Therefore, $\xi z^{i}$ satisfies the admissibility constraint for this $j, s, t$. This implies that for $m \geq$ $\max _{j, s, t} m_{t}(s)_{j}, \xi \dot{z}^{i}$ is $\left(C^{i}, p_{m}, q_{m}, \alpha_{m}\right)$-admissible and hence $\left(\xi \dot{x}^{i}, \xi \dot{z}^{i}\right) \in B^{i}\left(p_{m}, q_{m}, \alpha_{m}\right)$.

From the optimality of $x_{m}^{i}$ and the continuity of $\succeq^{i}$ we conclude that $x^{i} \succeq^{i} \dot{x}^{i}$, as desired.

To define the aggregate extended demand correspondence, I use the concept of an extended demand set. The extended demand set extends the demand set to incorporate information on loss and debt associated with an optimal consumption and portfolio plan. Formally, let $(p, q, \alpha)$ be a price and default rate system. Fix $n \geq 1$. Let $z^{i}$ be a portfolio plan for agent $i$. Define $\hat{\gamma}_{n}^{i}\left(p, q, \alpha, z^{i}\right)_{t}(s)_{j}=\max \left(\gamma^{i}\left(p, q, \alpha, z^{i}\right)_{t}(s)_{j}, \frac{1}{n}\right)$ and $\hat{\beta}_{n}^{i}\left(p, q, \alpha, z^{i}\right)_{t}(s)_{j}$ by replacing $\gamma^{i}\left(p, q, \alpha, z^{i}\right)_{t}(s)_{j}$ in the definition of $\beta^{i}\left(p, q, \alpha, z^{i}\right)_{t}(s)_{j}$ by $\hat{\gamma}_{n}^{i}\left(p, q, \alpha, z^{i}\right)_{t}(s)_{j}$. For $n=\infty$, the definition remains the same but with the convention that $\frac{1}{\infty}=0$. For $n \geq 1$, including $n=\infty$, the $n$-extended demand set for agent $i$ is

$$
\mathcal{D}_{n}^{i}(p, q, \alpha)=\left\{\begin{array}{l|l}
\left(x^{i}, z^{i} ; \hat{\beta}^{i}, \hat{\gamma}^{i}\right) \in X \times Z \times \mathcal{R}_{+}^{J} \times \mathcal{R}_{+}^{J} & \begin{array}{l}
\left(x^{i}, z^{i}\right) \in D^{i}(p, q, \alpha) \text { and for every } j, s, t, \\
\hat{\beta}_{t}^{i}(s)_{j}=\hat{\beta}_{n}^{i}\left(p, q, \alpha, z^{i}\right)_{t}(s)_{j}, \\
\hat{\gamma}_{t}^{i}(s)_{j}=\hat{\gamma}_{n}^{i}\left(p, q, \alpha, z^{i}\right)_{t}(s)_{j}
\end{array}
\end{array}\right\} .
$$

To every $(p, q, \alpha)$ in $\Delta \times \nabla$ the $n$-extended demand correspondence for agent $i$ associates the $n$-extended demand set $\mathcal{D}_{n}^{i}(p, q, \alpha)$ and the $n$-aggregate extended demand correspondence associates the set $\int_{I} \mathcal{D}_{n}^{i}(p, q, \alpha) d i$.

From the previous lemma, it is easy to see that for each $n$, including $n=\infty, \mathcal{D}_{n}^{i}$ has closed graph on $\left(\Delta \backslash P_{0}\right) \times \nabla$. In addition to this, if a price and default rate system $(p, q, \alpha)$ satisfies $p \gg 0$ and $q_{t} \gg 0$ (for $t \leq T-1$ ), then $\mathcal{D}_{n}^{i}$ is uniformly bounded (over $i$ ) on a neighborhood of $(p, q, \alpha)$ so that by Proposition D.II.8 in Hildenbrand (1974) (p.73), $\int_{I} \mathcal{D}_{n}^{i}(p, q, \alpha) d i$ has closed graph at $(p, q, \alpha)$. Also, because the measure on agents is atomless, $\int_{I} \mathcal{D}_{n}^{i}(p, q, \alpha) d i$ is a convex subset of $X \times Z \times \mathcal{R}_{+}^{J} \times \mathcal{R}_{+}^{J}$. Finally, it is easy to see that if $\left(p_{n}, q_{n}, \alpha_{n}, x_{n}^{i}, z_{n}^{i}, \hat{\beta}_{n}^{i}, \hat{\gamma}_{n}^{i}\right) \rightarrow\left(p, q, \alpha, x^{i}, z^{i}, \beta^{i}, \gamma^{i}\right)$ with $\left(p_{n}, q_{n}\right)$ and 
$(p, q)$ not in $P_{0}$ and if $\left(x_{n}^{i}, z_{n}^{i}, \hat{\beta}_{n}^{i}, \hat{\gamma}_{n}^{i}\right) \in D_{n}^{i}\left(p_{n}, q_{n}, \alpha_{n}\right)$ then $\left(x^{i}, z^{i}, \beta^{i}, \gamma^{i}\right) \in \mathcal{D}_{\infty}^{i}(p, q, \alpha){ }^{26} \quad$ The role of the aggregate extended demand correspondence is to aggregate individual demand and the associated loss and debt to yield the aggregate demand and the corresponding aggregate loss and aggregate debt in the economy.

Second, let us look at the price correspondence and some of its properties. Consider, for a fixed aggregate demand in period $t$, the function which assigns to each price in period $t$ the value of excess demand. Formally, for every $n \geq L+J$ and $n \neq \infty$, every $t$ and every $\left(x_{t}, z_{t}\right) \in X_{t} \times Z_{t}$, let $v_{t}\left(x_{t}, z_{t}\right): \hat{\Delta}_{n, t} \rightarrow \mathcal{R}_{t}$ be given by $\left(p_{t}, q_{t}\right) \mapsto\left(p_{t}(s) \zeta_{t}(s)+q_{t}(s) z_{t}(s)\right)_{s=1}^{S}$, where $\zeta_{t}(s)=x_{t}(s)-$ $\int_{I} w_{t}^{i}(s) d i$. The $n$-price correspondence in period $t, \theta_{n, t}: X_{t} \times Z_{t} \rightarrow \hat{\Delta}_{n, t}$, is given by $\left(x_{t}, z_{t}\right) \mapsto$ $\left\{\left(p_{t}, q_{t}\right) \in \hat{\Delta}_{n, t} \mid\left(p_{t}, q_{t}\right) \in \operatorname{argmax} v_{t}\left(x_{t}, z_{t}\right)\right\}$. The $n$-price correspondence, $\Theta_{n}: X \times Z \rightarrow \hat{\Delta}_{n}$, associates to each $(x, z)$ the set $\underset{t=1}{\times} \theta_{n, t}\left(x_{t}, z_{t}\right)$. To see that for every $n \geq L+J$ and $n \neq \infty$, the $n$-price correspondence has closed graph and takes non-empty and convex values in a compact set it is sufficient to state a fact that is easy to prove - for every such $n$ and for every $t, \theta_{n, t}$ has closed graph and takes non-empty and convex values in a compact set. The role of the price correspondence is the same as that of its counterpart in the Arrow-Debreu economy. In the words of Debreu (1959) (p.83), the price correspondence "prompts one, when trying to reduce positive excess demands, to put the weight of the price system on those commodities for which the excess demand is the greatest."

Third, let us look at the default rate correspondence and some of its properties. Fix $n \geq 1$ and $n \neq \infty$. For each $(\beta, \gamma) \in R_{+} \times R_{+}$let $\hat{\gamma}_{n}=\max \left(\gamma, \frac{1}{n}\right)$ and let $\phi_{n}(\beta, \gamma)=\left\{\min \left(\frac{\beta}{\hat{\gamma}_{n}}, 1\right)\right\}$. Also, let

$$
\phi_{\infty}(\beta, \gamma)= \begin{cases}\left\{\min \left(\frac{\beta}{\gamma}, 1\right)\right\} & \text { if } \gamma>0, \\ \{1\} & \text { if } \gamma=0 \text { and } \beta>0 \\ {[0,1]} & \text { if } \gamma=0 \text { and } \beta=0\end{cases}
$$

Then, for every $n \geq 1$ and $n \neq \infty, \phi_{n}$ is a continuous correspondence with non-empty, compact and convex values. Also, it is easy to see that $\phi_{\infty}$ has closed graph and takes non-empty, compact and convex values. For every $n$, including $n=\infty$, the $n$-default rate correspondence in period $t=1, \phi_{n, 1}:\left(\mathcal{R}_{1}^{J}\right)_{+} \times\left(\mathcal{R}_{1}^{J}\right)_{+} \rightarrow \nabla_{1}$, is the correspondence which is identically zero and in period $t \geq 2, \phi_{n, t}:\left(\mathcal{R}_{t}^{J}\right)_{+} \times\left(\mathcal{R}_{t}^{J}\right)_{+} \rightarrow \nabla_{t}$, is the correspondence which associates to each $\left(\beta_{t}, \gamma_{t}\right)$ the set $\times \phi_{n}\left(\beta_{t}(s)_{j}, \gamma_{t}(s)_{j}\right)$. The $n$-default rate correspondence, $\Phi_{n}: \mathcal{R}_{+}^{J} \times \mathcal{R}_{+}^{J} \rightarrow \nabla$, associates to $\underline{j, s}$

\footnotetext{
${ }^{26}$ It is helpful to keep in mind the elementary fact that for a sequence $\gamma_{n} \in R_{+}$, if we let $\hat{\gamma}_{n}=\max \left(\gamma_{n}, \frac{1}{n}\right)$ then $\hat{\gamma}_{n} \rightarrow \gamma \Leftrightarrow \gamma_{n} \rightarrow \gamma$.
} 
each $(\beta, \gamma)$ the set $\underset{t=1}{\stackrel{T}{\times}} \phi_{n, t}\left(\beta_{t}, \gamma_{t}\right)$.

From the properties of $\phi_{n}$, it follows that for every $n, \Phi_{n}$ has closed graph and takes nonempty, compact and convex values. As in the case of the $n$-extended demand correspondence, it is easy to see that for any sequence $\left(\beta_{n}, \gamma_{n}, \alpha_{n}\right) \in \mathcal{R}_{+}^{J} \times \mathcal{R}_{+}^{J} \times \nabla$, if $\left(\beta_{n}, \gamma_{n}, \alpha_{n}\right) \rightarrow(\beta, \gamma, \alpha)$ and $\alpha_{n} \in \Phi_{n}\left(\beta_{n}, \gamma_{n}\right)$ then $\alpha \in \Phi_{\infty}(\beta, \gamma)$. The role of the default rate correspondence is to use aggregate loss and debt in the economy to compute the default rate.

These three correspondences summarize the relevant information in the economy. To ensure that the demand correspondence takes non-empty values and that we are working with a compact and convex space, let us check that for any fixed $n \geq L+J$ and $n \neq \infty$, when prices and default rates are in $\hat{\Delta}_{n} \times \nabla$, the actions of agents and the integrals of these actions lie in a fixed, non-empty, compact and convex subset of a Euclidean space, independent of elements in $\hat{\Delta}_{n} \times \nabla$.

The bound on asset sales shows that the set of admissible portfolios is bounded below independent of $i$, independent of prices in $\hat{\Delta}_{n}$, independent of $\alpha$ and independent of $n(n \neq \infty)$. Also, since asset prices are strictly positive, the set of affordable portfolios is bounded above. Since individual endowments lie in a bounded set, this bound can be taken independent of $i$. Thus, the set of affordable and admissible portfolio plans and their integrals lies in a non-empty, compact, convex set $\hat{Z}_{n} \subset Z$ which is bounded below independent of $n$.

By definition, the set of consumption plans is bounded below by 0 . Since individual endowments lie in a bounded set and the set of affordable portfolio plans is bounded (independent of $i,(p, q) \in \hat{\Delta}_{n}$ and $\alpha$ ), the set of affordable consumption plans is bounded above (independent of $i,(p, q) \in \hat{\Delta}_{n}$ and $\alpha$ ). Thus, the set of affordable consumption plans and their integrals lies in a non-empty, compact, convex set $\hat{X}_{n} \subset X$ which is bounded below by 0 .

Also, by definition, loss from any agent is bounded below by 0 . Since the set of affordable portfolio plans is bounded below (independent of $i,(p, q) \in \hat{\Delta}_{n}$ and $\alpha$ ), loss from any agent is bounded above (independent of $i,(p, q) \in \hat{\Delta}_{n}$ and $\alpha$ ). Thus, potential loss from agents and potential aggregate loss in the economy lie in a non-empty, compact, convex set $\hat{\mathcal{R}}_{n} \subset \mathcal{R}^{J}$ which is bounded below by 0 . Similarly, potential debt owed to agents and potential aggregate debt in the economy lie in a non-empty, compact, convex subset of $\mathcal{R}^{J}$. If necessary, let us replace $\hat{\mathcal{R}}_{n}$ by a larger compact, convex subset of $\mathcal{R}^{J}$ that is bounded below by zero to conclude that potential debt owed to any agent and potential aggregate debt in the economy also lie in $\hat{\mathcal{R}}_{n}$.

To summarize, for $n \geq(L+J)$ and $n \neq \infty$, on $\hat{\Delta}_{n} \times \nabla$, the set of individual consumption and portfolio plans and their integrals lies in $\hat{X}_{n} \times \hat{Z}_{n}$ and the set of potential loss, potential debt and 
their integrals lies in $\hat{\mathcal{R}}_{n} \times \hat{\mathcal{R}}_{n}$.

Consider the correspondence $\Psi_{n}$ on $\hat{\Delta}_{n} \times \nabla \times \hat{X}_{n} \times \hat{Z}_{n} \times \hat{\mathcal{R}}_{n} \times \hat{\mathcal{R}}_{n}$ given by $\Psi_{n}=\Psi_{n}^{1} \times \Psi_{n}^{2} \times \Psi_{n}^{3}$, where, $\Psi_{n}^{1}: \hat{\Delta}_{n} \times \nabla \rightarrow \hat{X}_{n} \times \hat{Z}_{n} \times \hat{\mathcal{R}}_{n} \times \hat{\mathcal{R}}_{n}$ is given by $\Psi_{n}^{1}(p, q, \alpha)=\int_{I} \mathcal{D}_{n}^{i}(p, q, \alpha) d i, \Psi_{n}^{2}: \hat{X}_{n} \times \hat{Z}_{n} \rightarrow$ $\hat{\Delta}_{n}$ is given by $\Psi_{n}^{2}(x, z)=\Theta_{n}(x, z)$ and $\Psi_{n}^{3}: \hat{\mathcal{R}}_{n} \times \hat{\mathcal{R}}_{n} \rightarrow \nabla$ is given by $\Psi_{n}^{3}(\beta, \gamma)=\Phi_{n}(\beta, \gamma)$. The properties of the three correspondences given earlier imply that $\Psi_{n}$ satisfies the hypotheses of Kakutani's theorem. For each $n \geq L+J$ and $n \neq \infty$, let $\left(p_{n}, q_{n}, \alpha_{n}, x_{n}, z_{n}, \hat{\beta}_{n}, \hat{\gamma}_{n}\right)$ be a fixed point of $\Psi_{n}$. Let us check that we can get a convergent subsequence from this sequence of fixed points and the limit of this subsequence gives us an equilibrium.

Obviously, $\left(p_{n}, q_{n}, \alpha_{n}\right)$ is a bounded sequence. Since $\left(x_{n}, z_{n}, \hat{\beta}_{n}, \hat{\gamma}_{n}\right) \in \int_{I} \mathcal{D}_{n}^{i}\left(p_{n}, q_{n}, \alpha_{n}\right) d i$, there exists, for almost every $i,\left(x_{n}^{i}, z_{n}^{i}\right) \in D^{i}\left(p_{n}, q_{n}, \alpha_{n}\right)$ such that

$$
\left(x_{n}, z_{n}\right)=\int_{I}\left(x_{n}^{i}, z_{n}^{i}\right) d i, \quad \hat{\beta}_{n}=\int_{I} \hat{\beta}_{n}^{i} d i \quad \text { and } \quad \hat{\gamma}_{n}=\int_{I} \hat{\gamma}_{n}^{i} d i .
$$

Here, $\left(\hat{\beta}_{n}^{i}\right)_{t}(s)_{j}$ is short for $\hat{\beta}_{n}^{i}\left(p_{n}, q_{n}, \alpha_{n}, z_{n}^{i}\right)_{t}(s)_{j}$ and $\left(\hat{\gamma}_{n}^{i}\right)_{t}(s)_{j}$ for $\hat{\gamma}_{n}^{i}\left(p_{n}, q_{n}, \alpha_{n}, z_{n}^{i}\right)_{t}(s)_{j}$. To see that $\left(x_{n}, z_{n}, \hat{\beta}_{n}, \hat{\gamma}_{n}\right)$ is bounded, let us use the following lemma.

Lemma 3. $\left(x_{n}, z_{n}\right)$ is a bounded sequence.

Proof. Let $\zeta_{n}^{i}=x_{n}^{i}-w^{i}$ and $\zeta_{n}=\int_{I} \zeta_{n}^{i} d i$. Then, it is sufficient to check that $\left(\zeta_{n}, z_{n}\right)$ is a bounded sequence. As $\zeta_{n}^{i} \geq-\left(\sup _{i} w^{i}\right)$ and $z_{n}^{i} \geq-\hat{z}, \zeta_{n}^{i}$ and $z_{n}^{i}$ are uniformly (for almost every $i$ ) bounded below, $\left(\zeta_{n}, z_{n}\right)$ is bounded below. For upper bounds, we can use induction on $\{1, \ldots, T\}$ as follows;

Step 1: $t=1$. We want to see that, for every $s,\left(\left(\zeta_{n}\right)_{1}(s),\left(z_{n}\right)_{1}(s)\right)$ is bounded above. Notice that, by $\Psi_{n}^{2}$, for every $\left(\left(p_{n}^{\prime}\right)_{1},\left(q_{n}^{\prime}\right)_{1}\right) \in \hat{\Delta}_{n, 1}$ and every $s$,

$$
\left(p_{n}^{\prime}\right)_{1}(s)\left(\zeta_{n}\right)_{1}(s)+\left(q_{n}^{\prime}\right)_{1}(s)\left(z_{n}\right)_{1}(s) \leq \int_{I}\left(p_{n}\right)_{1}(s)\left(\zeta_{n}^{i}\right)_{1}(s)+\left(q_{n}\right)_{1}(s)\left(z_{n}^{i}\right)_{1}(s) d i=0 .
$$

Fix $s$ arbitrarily and let $\left(\left(p_{n}^{\prime}\right)_{1}(s),\left(q_{n}^{\prime}\right)_{1}(s)\right)=\left(\frac{n-(L+J-1)}{n}, \frac{1}{n}, \cdots, \frac{1}{n} ; \frac{1}{n}, \cdots, \frac{1}{n}\right)$. Then,

$$
\frac{n-(L+J-1)}{n}\left(\zeta_{n}\right)_{1}(s)_{1} \leq \frac{1}{n}\left(\left\|\int_{I} w_{1}^{i}(s) d i\right\|_{1}+\left\|\int_{I} \hat{z}_{1}(s) d i\right\|_{1}\right) .
$$

Thus, $\left(\zeta_{n}\right)_{1}(s)_{1}$ is bounded above. Using the same argument with different indices we see that, for every $\ell, j,\left(\zeta_{n}\right)_{1}(s)_{\ell}$ and $\left(z_{n}\right)_{1}(s)_{j}$ are bounded above. Since $s$ is arbitrary, step 1 is complete.

Step 2: Induction. Suppose that for every $s,\left(\left(\zeta_{n}\right)_{t-1}(s),\left(z_{n}\right)_{t-1}(s)\right)$ is bounded above. We want to see that for every $s,\left(\left(\zeta_{n}\right)_{t}(s),\left(z_{n}\right)_{t}(s)\right)$ is bounded above. Notice that the disposable income in period $t$, state $s$, of almost every agent satisfies

$$
W^{i}\left(p_{n}, q_{n}, \alpha_{n}, z_{n}^{i}\right)_{t}(s) \leq\left(p_{n}\right)_{t}(s) w_{t}^{i}(s)+\left[A_{t}(s)+\left(q_{n}\right)_{t}(s)\right]\left(z_{n}^{i}\right)_{t-1}(s)_{+} .
$$


Again, by $\Psi_{n}^{2}$, for every $\left(\left(p_{n}^{\prime}\right)_{t},\left(q_{n}^{\prime}\right)_{t}\right) \in \hat{\Delta}_{n, t}$ and for every $s$,

$$
\left(p_{n}^{\prime}\right)_{t}(s)\left(\zeta_{n}\right)_{t}(s)+\left(q_{n}^{\prime}\right)_{t}(s)\left(z_{n}\right)_{t}(s) \leq\left[A_{t}(s)+\left(q_{n}\right)_{t}(s)\right] \int_{I}\left(z_{n}^{i}\right)_{t-1}(s)_{+} d i
$$

Fix $s$ arbitrarily and let $\left(\left(p_{n}^{\prime}\right)_{t}(s),\left(q_{n}^{\prime}\right)_{t}(s)\right)=\left(\frac{n-(L+J-1)}{n}, \frac{1}{n}, \cdots, \frac{1}{n} ; \frac{1}{n}, \cdots, \frac{1}{n}\right)$. Then, $\frac{n-(L+J-1)}{n}\left(\zeta_{n}\right)_{t}(s)_{1} \leq \frac{1}{n}\left(\left\|\int_{I} w_{t}^{i}(s) d i\right\|_{1}+\left\|\int_{I} \hat{z}_{t}(s) d i\right\|_{1}\right)+\left[A_{t}(s)+\left(q_{n}\right)_{t}(s)\right] \int_{I}\left(z_{n}^{i}\right)_{t-1}(s)_{+} d i$.

Thus, $\left(\zeta_{n}\right)_{t}(s)_{1}$ is bounded above. Using the same argument with different indices we see that, for every $\ell, j,\left(\zeta_{n}\right)_{t}(s)_{\ell}$ and $\left(z_{n}\right)_{t}(s)_{j}$ are bounded above. Since $s$ is arbitrary, step 2 is complete.

From the boundedness of $\left(x_{n}, z_{n}\right)$, we can deduce that $\left(\hat{\beta}_{n}, \hat{\gamma}_{n}\right)$ is a bounded sequence. Therefore, the sequence $\left(p_{n}, q_{n}, \alpha_{n}, x_{n}, z_{n}, \hat{\beta}_{n}, \hat{\gamma}_{n}\right)$ is bounded. Replacing this sequence with a convergent subsequence, suppose that this sequence converges to $(p, q, \alpha, x, z, \beta, \gamma)$. The next lemma implies that $p \gg 0$.

Lemma 4. The sequence $\left(p_{n}\right)$ is bounded away from 0 .

Proof. Let

$F_{1}=\left\{i \in I \mid\right.$ for all $\left.n,\left(x_{n}^{i}, z_{n}^{i}\right) \in D^{i}\left(p_{n}, q_{n}, \alpha_{n}\right)\right\}$ and $F_{2}=\left\{i \in I \mid\right.$ for all $\left.\ell, s, t, \sup _{n}\left(x_{n}^{i}\right)_{t}(s)_{\ell}<\infty\right\}$

Then $\mu\left(F_{1} \cap F_{2}\right)=\mu(I)$. Fix $s, t$ arbitrarily. Then it is sufficient to prove that $\left(p_{n}\right)_{t}(s)$ is bounded away from 0 .

Suppose $\left(p_{n}\right)_{t}(s) \rightarrow 0$. Then, because $\left\|\left(\left(p_{n}\right)_{t}(s),\left(q_{n}\right)_{t}(s)\right)\right\|_{1}=1$, it must be that $t \leq T-1$ and also that there is $j$ and a (relabeled) subsequence such that for all $n,\left(q_{n}\right)_{t}(s)_{j} \geq \frac{1}{2 J}$. Therefore, $F_{3}=\left\{i \in I \mid \inf _{n} C^{i}\left(q_{n}, \beta_{n}\right)_{t}(s)_{j}>0\right\}$ satisfies $\mu\left(F_{3}\right)>0$. This implies that $F_{1} \cap F_{2} \cap F_{3}$ is not empty. For each $i$ in this intersection, agent $i$ can buy one unit more of each good in period $t$, state $s$ by giving up an arbitrarily small amount of consumption in period $t+1$, state $s$. But then, by strong monotonicity and continuity, for all $n$ sufficiently large, we get a contradiction to $\left(x_{n}^{i}, z_{n}^{i}\right) \in D^{i}\left(p_{n}, q_{n}, \alpha_{n}\right)$. Therefore, $\left(p_{n}\right)_{t}(s) \not \rightarrow 0$. In this case the income of almost every agent is bounded away from zero. Using the same argument as in the standard Arrow-Debreu model, we conclude that $\left(p_{n}\right)_{t}(s)$ is bounded away from 0 as desired.

This lemma implies that $p \gg 0$. Combined with the fact (see proof of the following lemma) that for every $j, s, t$, if $q_{t}(s)_{j}=0$ then $\int_{I}\left(z_{t}^{i}(s)_{+}\right)_{j} d i=\int_{I}\left(z_{t}^{i}(s)_{-}\right)_{j} d i=z_{t}(s)_{j}=0$, it follows that $\left(x_{n}^{(\cdot)}, z_{n}^{(\cdot)}, \hat{\beta}_{n}^{(\cdot)}, \hat{\gamma}_{n}^{(\cdot)}\right)$ is a uniformly bounded (for almost every $i$ ) and uniformly integrable sequence so that, using Lemma D.II.3 in Hildenbrand (1974) (p.69), we conclude that there is an integrable 
function $\left(\dot{x}^{i}, \dot{z}^{i}, \dot{\beta}^{i}, \dot{\gamma}^{i}\right)_{i \in I}$ such that, for almost every $i$,

$$
\left(\dot{x}^{i}, \dot{z}^{i}, \dot{\beta}^{i}, \dot{\gamma}^{i}\right) \in L s_{n}\left(x_{n}^{i}, z_{n}^{i}, \hat{\beta}_{n}^{i}, \hat{\gamma}_{n}^{i}\right) \quad \text { and } \quad \int_{I}\left(\dot{x}^{i}, \dot{z}^{i}, \dot{\beta}^{i}, \dot{\gamma}^{i}\right) d i=(x, z, \beta, \gamma)
$$

Here, $L s_{n}$ is the set of cluster points of the sequence $\left(x_{n}^{i}, z_{n}^{i}, \hat{\beta}_{n}^{i}, \hat{\gamma}_{n}^{i}\right)$. From properties of the $n$ extended demand correspondence, we conclude that $\left(\dot{x}^{i}, \dot{z}^{i}, \beta^{i}, \dot{\gamma}^{i}\right) \in \mathcal{D}_{\infty}^{i}(p, q, \alpha)$ from which it follows that for almost every $i$ there exists $\left(x^{i}, z^{i}\right) \in D^{i}(p, q, \alpha)$ such that $\left(x^{i}, z^{i}, \beta^{i}, \gamma^{i}\right)=\left(\dot{x}^{i}, \dot{z}^{i}, \beta^{i}, \dot{\gamma}^{i}\right)$ and $\int_{I}\left(x^{i}, z^{i}, \beta^{i}, \gamma^{i}\right) d i=(x, z, \beta, \gamma)$.

Let us check that $\left(p, q, \alpha ;\left(x^{i}, z^{i}\right)_{i \in I}\right)$ is an equilibrium. Since, for almost every $i,\left(x^{i}, z^{i}\right) \in$ $D^{i}(p, q, \alpha)$, the first condition in the definition of equilibrium is satisfied. To see that the second and third conditions in the definition of equilibrium are satisfied, let us use the following lemma.

Lemma 5. For every $t \leq T-1$ and every $j, s, \quad \zeta_{t}(s)=0, \quad z_{t}(s)=0 \quad$ and $\quad \alpha_{t+1}(s)_{j} \gamma_{t+1}(s)_{j}=$ $\beta_{t+1}(s)_{j}$. For $t=T$ and every $s, \quad \zeta_{T}(s)=0 \quad$ and $\quad z_{T}(s)=0$.

Proof. Let us use induction on $\{1, \ldots, T-1\}$ as follows;

Step 1: $t=1$. We want to see that, for every $j, s, \zeta_{1}(s)=0, z_{1}(s)=0$, and $\alpha_{2}(s)_{j} \gamma_{2}(s)_{j}=$ $\beta_{2}(s)_{j}$. Fix $s$ arbitrarily. From Lemma 3 , we see that $\zeta_{1}(s) \leq 0$ and $z_{1}(s) \leq 0$.

Also, $p_{1}(s) \zeta_{1}(s)+q_{1}(s) z_{1}(s)=\lim _{n} \int_{I}\left(p_{n}\right)_{1}(s)\left(\zeta_{n}^{i}\right)_{1}(s)+\left(q_{n}\right)_{1}(s)\left(z_{n}^{i}\right)_{1}(s) d i=0$. Combined with $p_{1}(s) \gg 0, q_{1}(s) \geq 0, \zeta_{1}(s) \leq 0$ and $z_{1}(s) \leq 0$, we have $\zeta_{1}(s)=0$ and for every $j$, if $q_{1}(s)_{j}>0$ then $z_{1}(s)_{j}=0$. Also, if $q_{1}(s)_{j}=0$ then for almost every $i,\left(z_{1}^{i}(s)_{-}\right)_{j}=0$ so that $0 \leq \int_{I}\left(z_{1}^{i}(s)_{+}\right)_{j} d i=$ $\int_{I} z_{1}^{i}(s)_{j} d i \leq z_{1}(s)_{j} \leq 0$.

To deduce that for every $j, \alpha_{2}(s)_{j} \gamma_{2}(s)_{j}=\beta_{2}(s)_{j}$, notice that $0 \leq \beta_{2}(s)_{j} \leq \gamma_{2}(s)_{j}$. Therefore, if $\gamma_{2}(s)_{j}=0$, then $\alpha_{2}(s)_{j} \gamma_{2}(s)_{j}=\beta_{2}(s)_{j}$. Otherwise, $\alpha_{2}(s)_{j} \in \phi_{\infty}\left(\beta_{2}(s)_{j}, \gamma_{2}(s)_{j}\right)=\left\{\frac{\beta_{2}(s)_{j}}{\gamma_{2}(s)_{j}}\right\}$. Since $s$ is arbitrary, step 1 is complete.

Step 2: Induction. Suppose that for every $j, s, \zeta_{t-1}(s)=0, z_{t-1}(s)=0, \alpha_{t}(s)_{j} \gamma_{t}(s)_{j}=\beta_{t}(s)_{j}$. We want to see that for every $j, s, \zeta_{t}(s)=0, z_{t}(s)=0$, and $\alpha_{t+1}(s)_{j} \gamma_{t+1}(s)_{j}=\beta_{t+1}(s)_{j}$. Fix $s$ arbitrarily. Let $\left(\left(p_{n}^{\prime}\right)_{t}(s),\left(q_{n}^{\prime}\right)_{t}(s)\right)=\left(\frac{n-(L+J-1)}{n}, \frac{1}{n}, \cdots, \frac{1}{n} ; \frac{1}{n}, \cdots, \frac{1}{n}\right)$. Then, by $\Psi_{n}^{2}$, we have,

$$
\begin{aligned}
\left(p_{n}^{\prime}\right)_{t} & (s)\left(\zeta_{n}\right)_{t}(s)+\left(q_{n}^{\prime}\right)_{t}(s)\left(z_{n}\right)_{t}(s) \\
\leq & \int_{I} W^{i}\left(p_{n}, q_{n}, \alpha_{n}, z_{n}^{i}\right)_{t}(s)-\left(p_{n}\right)_{t}(s) w_{t}^{i}(s) d i \\
= & \int_{I} \max \left((\epsilon-f)^{i}\left(p_{n}, q_{n}, \alpha_{n}, z_{n}^{i}\right)_{t}(s), 0\right)+f^{i}\left(p_{n}, q_{n}, \alpha_{n}, z_{n}^{i}\right)_{t}(s)-\left(p_{n}\right)_{t}(s) w_{t}^{i}(s) d i \\
= & \sum_{j}\left[\int_{I}\left(\beta_{n}^{i}\right)_{t}(s)_{j} d i-\left(\alpha_{n}\right)_{t}(s)_{j} \int_{I}\left(p_{n}\right)_{t}(s)_{1}\left[A_{t}(s)_{j}+\left(q_{n}\right)_{t}(s)_{j}\right]\left(\left(z_{n}^{i}\right)_{t-1}(s)_{+}\right)_{j} d i\right] \\
& +\left(p_{n}\right)_{t}(s)_{1}\left[A_{t}(s)+\left(q_{n}\right)_{t}(s)_{j}\right]\left(z_{n}\right)_{t-1}(s) \\
= & \sum_{j}\left(\beta_{n}\right)_{t}(s)_{j}-\left(\alpha_{n}\right)_{t}(s)_{j}\left(\gamma_{n}\right)_{t}(s)_{j}+\left[1-\left(\alpha_{n}\right)_{t}(s)_{j}\right]\left(p_{n}\right)_{t}(s)_{1}\left[A_{t}(s)_{j}+\left(q_{n}\right)_{t}(s)_{j}\right]\left(z_{n}\right)_{t-1}(s)_{j} .
\end{aligned}
$$


It follows that $\zeta_{t}(s)_{1}=\lim _{n}\left(\zeta_{n}\right)_{t}(s)_{1} \leq 0$. Using the same argument with different indices we see that $\zeta_{t}(s) \leq 0$ and $z_{t}(s) \leq 0$.

Analogous to step 1, we have $p_{t}(s) \gg 0, q_{t}(s) \geq 0, \zeta_{t}(s) \leq 0, z_{t}(s) \leq 0, p_{t}(s) \zeta_{t}(s)+q_{t}(s) z_{t}(s)=0$ and $q_{t}(s)_{j}=0 \Rightarrow z_{t}(s)_{j}=\int_{I}\left(z_{t}^{i}(s)_{+}\right)_{j} d i=\int_{I}\left(z_{t}^{i}(s)_{-}\right)_{j} d i=0$. Thus, $\zeta_{t}(s)=0$ and $z_{t}(s)=0$. As in step 1 , we see that for every $j, 0 \leq \beta_{t+1}(s)_{j} \leq \gamma_{t+1}(s)_{j}$ and that $\alpha_{t+1}(s)_{j} \gamma_{t+1}(s)_{j}=\beta_{t+1}(s)_{j}$. Since $s$ is arbitrary, step 2 is complete. Finally, the argument showing $\zeta_{t}(s)=0$ and $z_{t}(s)=0$ also works for $t=T$.

This lemma implies that the second and third conditions in the definition of equilibrium are also satisfied. Therefore, $\left(p, q, \alpha ;\left(x^{i}, z^{i}\right)_{i \in I}\right)$ is an equilibrium. To see that the second theorem is true, let us use the following lemma.

Lemma 6. Suppose there is $s, t$ such that $e_{t}(s)<\inf _{i} w_{t}^{i}(s)$. Then for every $j, \alpha_{t}(s)_{j}<1$.

Proof. Since $p_{n}$ is bounded away from zero, $\left(p_{n}\right)_{t}(s)\left(\inf _{i} w_{t}^{i}(s)-e_{t}(s)\right)$ is also bounded away from zero. Let $0<\delta<1$ be such that for all $n,\left(p_{n}\right)_{t}(s)\left(\inf _{i} w_{t}^{i}(s)-e_{t}(s)\right) \geq \delta$. Then $\lambda\left(p_{n}, q_{n}, \alpha_{n}, z_{n}^{i}\right)_{t}(s) \leq$ $\max \left(\left(p_{n}\right)_{t}(s)_{1}\left[A_{t}(s)+\left(q_{n}\right)_{t}(s)\right]\left(z_{n}^{i}\right)_{t-1}(s)_{-}-\delta, 0\right)$ and for every $n$ such that the denominator of the following fraction is not zero,

$$
\frac{\max \left(\left(p_{n}\right)_{t}(s)_{1}\left[A_{t}(s)+\left(q_{n}\right)_{t}(s)\right]\left(z_{n}^{i}\right)_{t-1}(s)_{-}-\delta, 0\right)}{\left(p_{n}\right)_{t}(s)_{1}\left[A_{t}(s)+\left(q_{n}\right)_{t}(s)\right]\left(z_{n}^{i}\right)_{t-1}(s)_{-}} \leq \frac{\max (\kappa-\delta, 0)}{\kappa} \leq 1-\frac{\delta}{\kappa}
$$

where $\kappa=\sup _{n}\left(p_{n}\right)_{t}(s)_{1}\left[A_{t}(s)+\left(q_{n}\right)_{t}(s)\right] \hat{z}_{t-1}(s)+1$. Therefore, for every $j$, almost every $i$ and every $n \geq L+J,\left(\hat{\beta}_{n}^{i}\right)_{t}(s)_{j} \leq\left(1-\frac{\delta}{\kappa}\right)\left(\hat{\gamma}_{n}^{i}\right)_{t}(s)_{j}$ whence $\alpha_{t}(s)_{j} \leq 1-\frac{\delta}{\kappa}$.

Now suppose there is $j, s, t$ such that $e_{t}(s)<\inf _{i} w_{t}^{i}(s)$ and $A_{t}(s)_{j}>0$. Then $t \geq 2$ and $\alpha_{t}(s)_{j}<1$ so that if $q_{t-1}(s)_{j}=0$ then the demand set of almost every agent is empty which contradicts the definition of an equilibrium. Thus, $q_{t-1}(s)>0, \alpha_{t}(s)<1$ and the equilibrium is non-trivial.

\section{Extensions and Conclusion}

In this section, I point out some ways in which we may modify and extend the model.

In the model, a credit limit is specified in units of the asset or in units of good $\ell=1$ (depending on the asset return matrix). However, we sometimes observe that a credit limit is specified in units of value. It is easy to modify the model to allow for admissibility of a portfolio plan to depend on value of promised delivery instead of quantity. If we rename admissibility in the model as quantity admissibility and call by value admissibility the admissibility of a portfolio plan depending on value 
of promised delivery and use these concepts to redefine the budget and demand sets, we get two definitions of equilibrium. However, every equilibrium with quantity admissibility is also an equilibrium with value admissibility and vice versa. (This is because strong monotonicity and continuity of preferences implies that in every equilibrium — whether with quantity or value admissibility the price of every good is positive. Therefore, the budget set with quantity admissibility and the one with value admissibility coincide and hence so do the demand sets.)

We can also extend the model to include assets which promise to pay in more than one good. This can be done as follows. The basic concepts, except the assumptions about payoffs of assets, remain the same. The payoffs of the assets in period $t$, state $s$ are summarized by a $L \times J$ matrix $A_{t}(s)$. Its $\ell j$-th component, $A_{t}(s)_{\ell, j}$, specifies the (non-negative) payoff of asset $j$ in pe$\operatorname{riod} t$, state $s$ in terms of good $\ell$. As in the model, assume that for every $s, A_{1}(s)$ is the zero matrix and to reflect the dependence of asset returns on the information available, assume that for every $t, A_{t}(\cdot)$ is $\mathcal{S}_{t}$-measurable. An asset structure is a collection of asset return matrices, $A=\left(A_{t}(s)\right)_{s, t}$. The rights of creditors and debtors remain the same. To determine the financial position of an agent, in all the definitions, pre-multiply $A_{t}(s)$ by $p_{t}(s)$ instead of $p_{t}(s)_{1}$. A credit limit for agent $i$ is a continuous function $C^{i}: Q \times \mathcal{R}_{+}^{J} \rightarrow \mathcal{R}_{+}^{L J}$ that is weakly decreasing in $\beta$. As in the model, assume the measurability and boundedness conditions and assume that for every $\ell, j, s, t$ with $t \leq T-1, \mu\left(\left\{i \in I \mid \inf _{q \in Q_{t}(s)_{j}, \beta \in \mathcal{R}_{+}^{J}} C^{i}(q, \beta)_{t}(s)_{\ell, j}>0\right\}\right)>0$ and if $q_{t}(s)_{j}=0$ then $\mu\left(\left\{i \in I \mid C^{i}(q, 0)_{t}(s)_{\ell, j}=0\right\}\right)=\mu(I)$. A portfolio plan $z^{i}$ is $\left(C^{i}, p, q, \alpha\right)$ - admissible if for every period $\ell, j, s, t$ with $t \leq T-1$,

if there is $s^{\prime} \in E_{t}(s)$ and $\ell^{\prime} \geq 1$ with $A_{t+1}\left(s^{\prime}\right)_{\ell^{\prime}, j}>0$ then $A_{t+1}(s)_{\ell, j}\left(z_{t}^{i}(s)_{-}\right)_{j} \leq C^{i}\left(q, \beta^{i}\left(p, q, \alpha, z^{i}\right)\right)_{t}(s)_{\ell, j}$ otherwise, $\quad\left(z_{t}^{i}(s)_{-}\right)_{j} \leq C^{i}\left(q, \beta^{i}\left(p, q, \alpha, z^{i}\right)\right)_{t}(s)_{\ell, j}$. The lemma on bound on asset sales remains true as stated. Its proof needs an obvious modification. The budget set, demand set, economy and equilibrium are defined as in the model. Theorem 1 remains true as stated. Theorem 2 is true if, everywhere in its statement, we replace $j$ by $\ell, j$. The proofs require minor and obvious modifications. The example obviously remains true. Thus, we can extend the model to include assets which promise to pay in more than one good.

We can also combine these modifications and extensions to derive a model in which assets promise delivery of many goods and in which admissibility of a portfolio plan depends on value of promised delivery. A version of the two theorems is true for any economy represented by this derived model and the examples given in the paper are valid.

To conclude, let us recall that using more realistic legal and economic institutions, the model 
in this paper incorporates bankruptcy in general equilibrium. In this model, there is unsecured lending, the rights of debtors and creditors are derived from the existing legal framework, an agent's default history affects his future trading opportunity and bankruptcy arises in a manner similar to what we observe. Every economy represented by this model has an equilibrium and with minor additional assumptions, every economy has a non-trivial equilibrium. This model is robust in the sense that using it, we can easily see well-known welfare effects of bankruptcy.

In future work, using this model and building on it, we can investigate in more detail the effects on competitive markets of different bankruptcy rules (exemptions, recovery rules, priority rules), of different credit limit systems (the weight that should be put on an agent's default history, on (expectations of) his future income, on riskiness of assets) and of chain reactions (the role of pessimistic expectations, controlling and mitigating the effects of such reactions, the role of credit limits and exemptions in propagating and controlling such reactions). This model puts us on the path to a better understanding of bankruptcy in general equilibrium and sends us on our way to a better understanding and design of financial and legal institutions that facilitate smooth functioning of competitive markets. 


\section{Appendix}

Table 1

$$
\begin{array}{ll}
U^{1}=x_{1}+x_{2}(1)+100 x_{2}(2) ; & w^{1}=(1,10,1) \\
U^{2}=x_{1}+100 x_{2}(1)+x_{2}(2) ; & w^{2}=(1,1,10)
\end{array}
$$

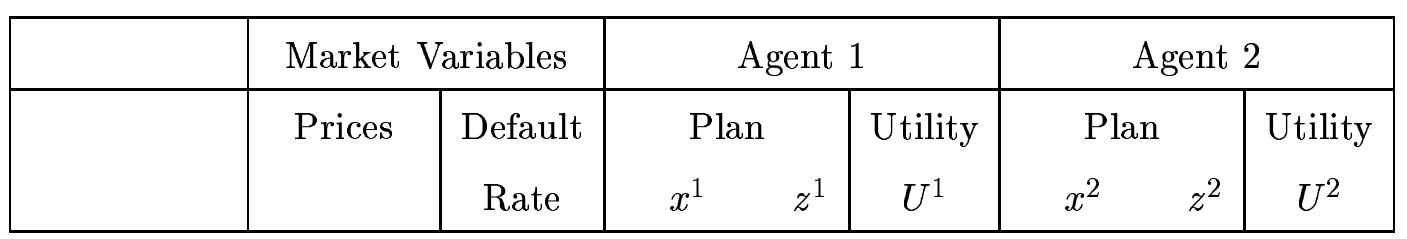

\begin{tabular}{|c|c|c|c|c|c|c|c|}
\hline GEI & $\left(\frac{1}{102}, \frac{101}{102}\right)$ & $(1,10,1)$ & 0 & 111 & $(1,1,10)$ & $c$ & 111 \\
\hline
\end{tabular}

\begin{tabular}{|l|l|l|l|l|l|l|}
\hline Endowment & & & $(1,10,1)$ & 111 & $(1,1,10)$ & 111 \\
\hline
\end{tabular}

$e(1)=1, e(2)=1, C^{1}(q)=C^{2}(q)=8 q$

\begin{tabular}{|c|c|c|cc|c|cc|c|}
\hline Bankruptcy & $\left(\frac{1}{2}, \frac{1}{2}\right)$ & $(0,1)$ & $(2,9,1)$ & -1 & 111 & $(0,2,10)$ & 1 & 210 \\
& $\left(\frac{1}{2}, \frac{1}{2}\right)$ & $(1,0)$ & $(0,10,2)$ & 1 & 210 & $(2,1,9)$ & -1 & 111 \\
\hline
\end{tabular}

$1 \leq e(1) \leq 6, e(2)=1, C^{1}(q)=C^{2}(q)=8 q$

\begin{tabular}{|c|c|c|cc|c|cc|c|}
\hline \multirow{2}{*}{ Bankruptcy } & $\left(\frac{1}{2}, \frac{1}{2}\right)$ & $(0,1)$ & $(2,9,1)$ & -1 & 111 & $(0,2,10)$ & 1 & 210 \\
& $\left(\frac{1}{2}, \frac{1}{2}\right)$ & $(1,0)$ & $(0,10,2)$ & 1 & 210 & $(2,1,9)$ & -1 & 111 \\
\hline
\end{tabular}

\begin{tabular}{|c|c|c|c|c|c|c|c|c|}
\hline Bankruptcy & $\left(\frac{1}{2}, \frac{1}{2}\right)$ & $(1,0)$ & $(0,10,2)$ & 1 & 210 & $(2,1,9)$ & -1 & 111 \\
\hline \multicolumn{9}{|c|}{$10 \leq e(1), 10 \leq e(2), \quad C^{1}(q)=C^{2}(q)=8 q$} \\
\hline Bankruptcy & $(1,0)$ & $(1,1)$ & $(1,10,1)$ & 0 & 111 & $(1,1,10)$ & 0 & 111 \\
\hline
\end{tabular}

$6<e(1)<10, e(2)=1, C^{1}(q)=C^{2}(q)=8 q$ 
Table 2

$$
\begin{array}{cc}
U^{1}=100 x_{1}+x_{2}(1)+50 x_{2}(2) ; & w^{1}=(1,10,1) \\
U^{2}=x_{1}+100 x_{2}(1)+x_{2}(2) ; & w^{2}=(10,1,0)
\end{array}
$$

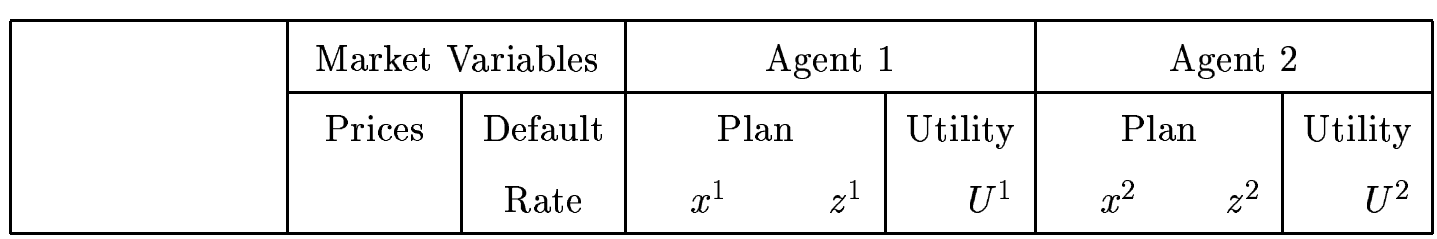

\begin{tabular}{|c|c|c|c|c|c|c|c|}
\hline Arrow-Debreu & $\left(\frac{2}{5}, \frac{2}{5}, \frac{1}{5}\right)$ & $(11,0,1)$ & & 1150 & $(0,11,0)$ & & 1100 \\
\hline GEI & $\left(\frac{1}{11}, \frac{10}{11}\right)$ & $(11,9,0)$ & -1 & 1109 & $(0,2,1)$ & 1 & 201 \\
\hline
\end{tabular}

\begin{tabular}{|l|l|l|l|l|l|l|}
\hline Endowment & & & $(1,10,1)$ & 160 & $(10,1,0)$ & 110 \\
\hline
\end{tabular}

\begin{tabular}{|c|c|c|c|c|c|c|c|c|}
\hline Bankruptcy & $\left(\frac{9}{19}, \frac{10}{19}\right)$ & $(0,1)$ & $(11,1,1)$ & -9 & 1151 & $(0,10,0)$ & 9 & 1000 \\
\hline
\end{tabular}

\begin{tabular}{|c|c|c|c|c|c|c|c|c|}
\hline Bankruptcy & $\left(\frac{1}{2}, \frac{1}{2}\right)$ & $(0,1)$ & $(11,0,1)$ & -10 & 1150 & $(0,11,0)$ & 10 & 1100 \\
\hline
\end{tabular}

The different parameterizations given in the text are summarized in the next page. 


\section{Parameterizations:}

- Let $e(1)=1, e(2)=1$ and for $\xi \in[1,9], \quad$ let $C^{1}(q)=\frac{(10+\xi) \xi}{10} q, C^{2}(q)=\frac{10+\xi}{10} q$. Then

$$
\begin{aligned}
& \left(p_{1}, q\right)=\left(\frac{\xi}{10+\xi}, \frac{10}{10+\xi}\right), \quad \alpha=(0,1), \\
& x^{1}=(11,10-\xi, 1), z^{1}=-\xi, \quad x^{2}=(0,1+\xi, 0), z^{2}=\xi
\end{aligned}
$$

is an equilibrium with utilities $\left(U^{1}, U^{2}\right)=(1160-\xi, 100+100 \xi)$.

- For $\xi \in[0,1]$, let $e(1)=\xi, e(2)=1, C^{1}(q)=\frac{(20-\xi)(10-\xi)}{10} q, C^{2}(q)=\frac{(20-\xi)(1-\xi)}{10} q$. Then

$$
\begin{aligned}
& \left(p_{1}, q\right)=\left(\frac{10-\xi}{20-\xi}, \frac{10}{20-\xi}\right), \quad \alpha=(0,1), \\
& x^{1}=(11, \xi, 1), z^{1}=\xi-10, \quad x^{2}=(0,11-\xi, 0), z^{2}=10-\xi
\end{aligned}
$$

is an equilibrium with utilities $\left(U^{1}, U^{2}\right)=(1150+\xi, 1100-100 \xi)$. 


\section{References}

Aghion, P., and B. Hermalin (1990): "Legal Restrictions on Private Contracts Can Enhance Efficiency," Journal of Law, Economics and Organization, 6(2), 381-409.

Alvarez, F., and U. Jermann (2000): "Efficiency, Equilibrium, and Asset Pricing with Risk of Default," Econometrica, 68(4), 775-797.

Araujo, A., And M. Pascoa (1999): "Bankruptcy in a Model of Unsecured Claims," mimeo.

Bernanke, B., M. Gertler, and S. Gilchrist (1996): "The Financial Accelerator and The Flight to Quality," The Review of Economics and Statistics, 78(1), 1-15.

Debreu, G. (1959): The Theory of Value. New York: Wiley.

Dubey, P., J. Geanakoplos, and M. Shubik (1997): "Default and Efficiency in a General Equilibrium Model with Incomplete Markets," Mimeo. Based on Cowles Foundation Discussion Paper No.713, 1990.

Dubey, P., J. Geanakoplos, and W. Zame (1997): "Collateral, Default and Market Crashes," Mimeo.

Dunscomb(Jr.), S. W. (1898): "The Federal Bankruptcy Law," Political Science Quarterly, $13(4), 606-616$.

Epstein, D. G. (1995): Bankruptcy and Other Debtor-Creditor Laws. West Publishing Co.

Hart, O., And J. Moore (1994): "A Theory of Debt Based on the Inalienability of Human Capital," qje, 109(4), 841-879.

Hildenbrand, W. (1974): Core and Equilibria of a Large Economy. Princeton University Press.

Kehoe, T., And D. Levine (1993): "Debt-Constrained Asset Markets," The Review of Economic Studies, 60(4), 865-888.

Kiyotaki, N., And J. Moore (1997): "Credit Cycles," Journal of Political Economy, 105(2), 211-248.

Kocherlakota, N. (1996): "Implications of Efficient Risk Sharing without Committment," The Review of Economic Studies, 63(4), 595-609. 
Magill, M., And M. QuinziI (1996): Theory of Incomplete Markets. MIT Press.

Modica, M., A. Rustichini, and J.-M. Tallon (1999): "Unawareness and Bankruptcy: A General Equilibrium Model," Economic Theory, 12.

Shubik, M. (1972): "Commodity Model, Oligopoly, Credit and Bankruptcy in a General Equilibrium Model," Western Economic Journal, 10, 24-38.

Shubik, M., And C. Wilson (1977): "The Optimal Bankruptcy Rule in a Trading Economy Using Fiat Money," Zeitschrift fur Nationaklokonomie (Journal of Economics), 37(3), 337-354, Reprinted as Cowles Foundation Paper No. 465.

Stiglitz, J., And A. Weiss (1981): "Credit Rationing in Markets with Imperfect Competition," American Economic Review, 71(3), 393-410.

Townsend, R. (1979): "Optimal Contracts and Competitive Markets with Costly State Verification," Journal of Economic Theory, 21(2), 265-293.

Wang, H.-J., And M. White (2000): "An Optimal Personal Bankruptcy Procedure and Proposed Reforms," Journal of Legal Studies, 29(1), 255-286.

Warren, C. (1935): Bankruptcy in United States History. Harvard University Press.

White, M. J. (1998): "Why Don't More Households File for Bankruptcy?," Journal of Law, Economics and Organization, 14(2), 205-231.

Zame, W. (1993): "Efficiency and the Role of Default When Security Markets are Incomplete," American Economic Review, 83(5), 1142-1164. 